\title{
Waveform modelling of local earthquakes in southwest Japan
}

\author{
Mohamed F. Abdelwahed and Dapeng Zhao \\ Geodynamics Research Center, Ehime University, Matsuyama 790-8577, Japan
}

(Received January 6, 2005; Revised June 10, 2005; Accepted July 8, 2005)

\begin{abstract}
The crustal structure beneath southwest Japan is investigated through waveform modellings of four local crustal earthquakes by using the generalized ray theory. High-quality seismograms recorded by the Hi-net seismic network are used. The focal mechanism solutions of the events used are estimated by using the first $P$-wave polarity data. Twenty-nine paths are used to characterize the crustal waveguide in SW Japan. Optimal 1-D velocity models for different paths are derived individually by waveform modelling. Synthetic tests are conducted to study the effects of different model parameters and to confirm the focal mechanism solutions. Modelling the waveforms individually is proven applicable for the heterogeneous regions. The resulted synthetics match the observed seismograms well. Considerable variations of the Conrad and Moho depths are found in the study area. The Conrad depth ranges from 14.8 to $19.7 \mathrm{~km}$, and the Moho depth ranges from 28.4 to $33.4 \mathrm{~km}$. Considerable variations in the crustal structure are found for the eastern portion of the study area where Biwa Lake lies. The effects of Biwa Lake on different paths are examined in detail.
\end{abstract}

Key words: Waveform modelling, generalized ray theory, synthetic seismogram, velocity structure, southwest Japan.

\section{Introduction}

Waveform modelling has become one of the most powerful tools for studying the Earth structure. Considerable progress has been made in the last two decades in improving the process of synthesizing seismograms and waveform modelling (e.g. Langston and Helmberger, 1975; Dreger and Helmberger, 1993; Zhao and Helmberger, 1994; Zhu and Helmberger, 1996). These studies have demonstrated that an adequate crustal velocity model which generates the recorded characteristics of regional waveforms can be used to retrieve the source parameters of earthquakes. Similarly, seismic velocity structure can be estimated by inverting waveforms of local and regional events (Dreger and Helmberger, 1990; Helmberger et al., 2001). Particularly, local and regional waveform modellings play an important role in studying the detailed crust and upper mantle structure. These waveforms are generally complicated due to the great influence of crust heterogeneities. This gives rise to additional reflected and converted body wave phases particularly at short periods (Dreger and Helmberger, 1993).

Regional seismic waves have proven to be amongst the most difficult to analyse or model in deterministic fashion in the field of seismology. At high frequencies, the effects of scattering in the crust become so intense that only the statistical properties of waveform are meaningful (Saikia et al., 2001). However, the high frequency $P_{n l}$ phases have some stable features which can be deterministically modelled to characterize the regional waveguide. The characteristics of $P_{n l}$ waves are due to their primarily sampling the lower

Copyright (c) The Society of Geomagnetism and Earth, Planetary and Space Sciences (SGEPSS); The Seismological Society of Japan; The Volcanological Society of Japan; The Geodetic Society of Japan; The Japanese Society for Planetary Sciences; TERRAPUB. crust and the Moho discontinuity, and consequently being relatively insensitive to the upper crust lateral heterogeneity (Saikia and Burdick, 1991). In this study, high-frequency $P$-waves at local distances are being modelled. The local waveforms are generally difficult to model precisely with a single 1-D model. Therefore, these high frequency waveforms are individually modelled to characterize the crustal waveguide for the area under study.

The generalized ray theory (GRT) (Helmberger, 1974, 1983 ) is widely used for various studies of waveform modelling. In California many waveform modelling studies have been conducted to determine earthquake focal mechanisms and the crust and upper mantle structure (e.g., Wallace et al., 1981; Dreger and Helmberger, 1990; Zhao and Helmberger, 1994; Zhu and Helmberger, 1996; Mori and Helmberger, 1996; Song and Helmberger, 1998; Jones and Helmberger, 1998; Helmberger et al., 2001; Savage et al., 2003). Thio et al. (1999) combined body waves with surface waves for modelling earthquake sources and the velocity structure of the western Mediterranean region using broadband waveform records.

The Japan subductions zone exhibits complex structure and tectonics. The crust and upper mantle structure under the Japan islands has been mainly studied by using seismic tomography (e.g., Zhao et al., 1994, 2000, 2002; Salah and Zhao, 2003). However, few studies have been made to investigate the velocity structure beneath Japan by using waveform modelling techniques. The purpose of this study is to apply the GRT technique to modelling local earthquake waveforms to retrieve the crustal velocity structure beneath SW Japan. 


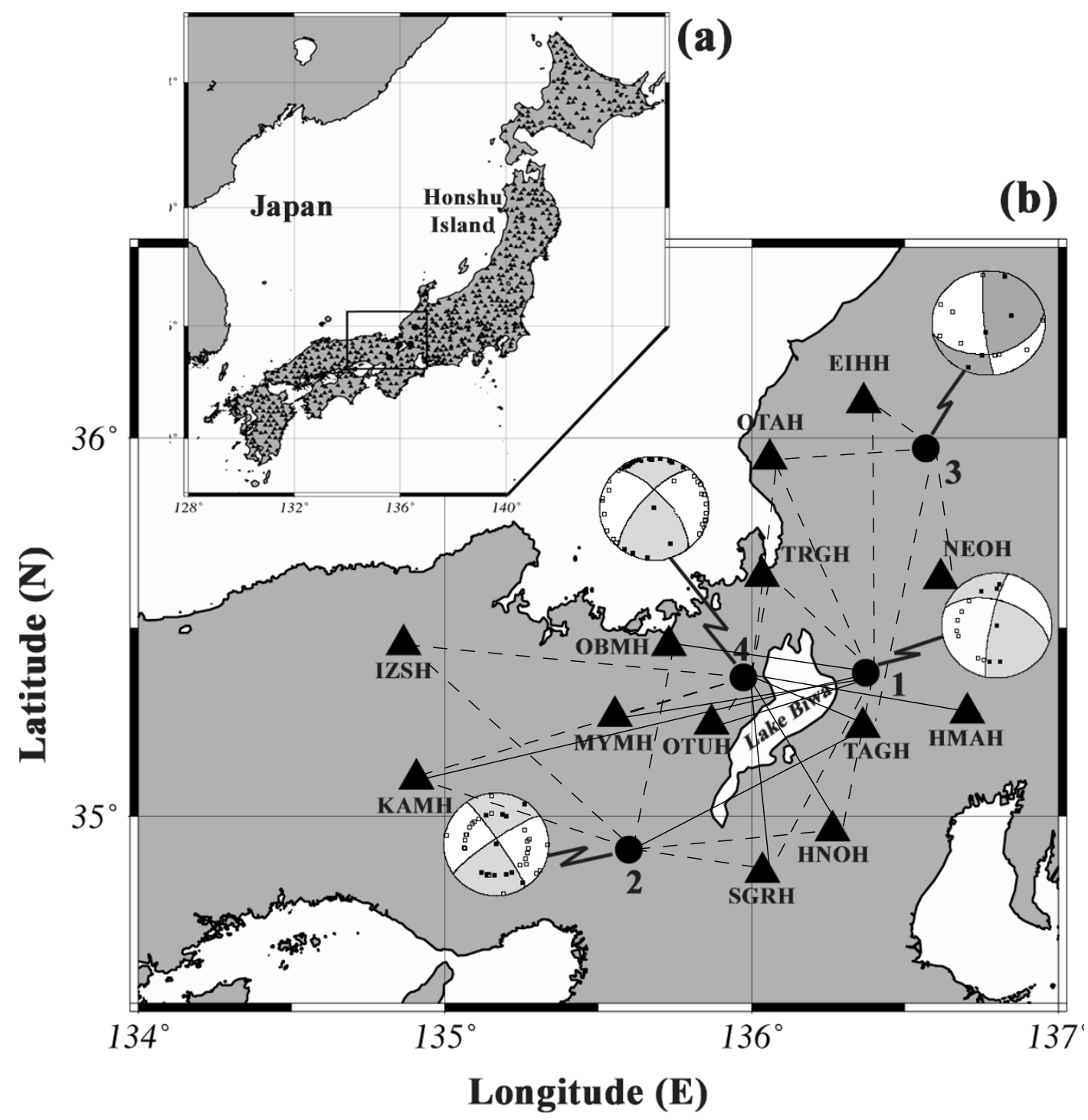

Fig. 1. (a) Map showing the present study area (box) and Hi-net seismic stations (solid triangles). (b) Solid circles and triangles denote earthquakes and seismic stations used in this study. Fault-plane solutions of the focal mechanisms for the earthquakes are also shown. Biwa paths and non-Biwa paths are denoted as solid and dashed lines, respectively.

\section{Data}

In this study we used waveform data of local crustal earthquakes recorded by the High-sensitivity Seismographic Network (Hi-net) operated by the National Research Institute for Earth Science and Disaster Prevention (NIED) in Japan (see Obara, 2002). The Hi-net is composed of about 690 short-period seismographic stations now installed throughout Japan (Fig. 1(a)). Each station consists of three-component velocity-type seismometers of natural frequency of $1 \mathrm{~Hz}$ installed at the bottom of a borehole with a depth of 100 to $200 \mathrm{~m}$. The data are digitized in each station with a sampling rate of $100 \mathrm{~Hz}$ and then transmitted to the data center after being attached with the absolute time information from the global positioning system clock.

Four shallow earthquakes are used in this study. Their magnitudes range from M2.6 to M3.4 and their depths range from 6 to $15 \mathrm{~km}$. The focal mechanisms of these events are determined by using the first $P$-wave polarity data. The hypocentral and source parameters are shown in Table 1. Figure 1(b) shows the location map of the study area and the hypocentral distribution of these events with their corresponding fault-plane solutions. Since these events are all small crustal earthquakes, their sources are considered simple and the rays mostly propagate in the upper and lower crust. The observed records are corrected instrumentally by deconvolving the poles and zeroes response of the Hinet (Scherbaum, 1996). Integration, appropriate filtering (Butterworth band-pass filters $0.2-4.0 \mathrm{~Hz}$ ) and rotation are also applied. Because seismic moments of these events are not known, normalized amplitudes of both the observed and synthetic seismograms are used.

The most significant feature of the present study area is Biwa Lake. It is located in the central part of Honshu Island (Fig. 1) and is the largest lake in Japan covering an area of $674 \mathrm{~km}^{2}$ with a maximum depth of $104 \mathrm{~m}$. The lake has two basins, the northern and southern basins. The northern basin is larger and deeper, which consists of two depressions more than $70 \mathrm{~m}$ deep and having an average depth of $48 \mathrm{~m}$ (for more details, see Ali et al., 1999).

In this study, we use waveform modelling to character- 
Table 1. Hypocentral parameters and focal mechanism solutions of the events used in this study.

\begin{tabular}{ccccccc}
\hline Event & O.T. & $\begin{array}{c}\text { Latitude } \\
(\mathrm{N})\end{array}$ & $\begin{array}{c}\text { Longitude } \\
(\mathrm{E})\end{array}$ & $\begin{array}{c}\text { Depth } \\
(\mathrm{km})\end{array}$ & $\mathrm{M}$ & $\begin{array}{c}\text { Mechanism } \\
\text { Strike/Dip/Slip }\end{array}$ \\
\hline 1 & $2002 / 05 / 08$ & 35.381 & 136.373 & 12.3 & 3.1 & $191 / 50 / 10$ \\
& $09: 48: 02.275$ & & & & & $290 / 51 / 12$ \\
2 & $2002 / 08 / 24$ & 34.911 & 135.600 & 13.0 & 2.4 & $240 / 73 / 25$ \\
& $17: 49: 23.934$ & & & & & $338 / 65 / 18$ \\
3 & $2002 / 09 / 10$ & 35.973 & 136.568 & 9.4 & 3.6 & $50 / 80 / 05$ \\
& $17: 54: 20.461$ & & & & & $174 / 83 / 50$ \\
4 & $2002 / 09 / 13$ & 35.369 & 135.974 & 15.0 & 3.4 & $219 / 77 / 15$ \\
& $07: 36: 03.059$ & & & & & $312 / 75 / 16$ \\
\hline
\end{tabular}

ize the crustal waveguide in SW Japan with adequate 1-D velocity models and examine the effect of Biwa Lake on different paths.

\section{Methodology}

The generalized ray theory (GRT) is used to generate synthetic seismograms for waveform modelling. GRT has an advantage that it can generate quickly the Green's function for describing the wave propagation at local and regional distances.

The principle of the GRT technique is to expand the generalized rays equations in conjunction with the Cagniard-de Hoop technique. This enables to construct Green's functions for a simple 1-D velocity structure. The Green's functions are constructed by summing generalized rays for a point shear dislocation. In cylindrical coordinates, consider $W_{i}(t), Q_{i}(t)$ and $V_{i}(t)$ which are the Green's functions for the three fundamental faults: strike slip, dip slip and $45^{\circ}$ dip slip, respectively. The vertical $(\boldsymbol{U}(\boldsymbol{t}))$, radial $(\boldsymbol{R}(\boldsymbol{t}))$ and tangential $(\boldsymbol{T}(\boldsymbol{t}))$ synthetic seismograms at the appropriate distance and source depth can be expressed as follows:

$$
\begin{aligned}
U(t) & =\frac{M o}{4 \pi \rho}\left(S(t) * \sum_{i=1}^{i=3} W_{i}(t) A_{i}(\theta, \lambda, \delta)\right) \\
T(t) & =\frac{M o}{4 \pi \rho}\left(S(t) * \sum_{i=1}^{i=2} V_{i}(t) A_{i+3}(\theta, \lambda, \delta)\right) \\
R(t) & =\frac{M o}{4 \pi \rho}\left(S(t) * \sum_{i=1}^{i=3} Q_{i}(t) A_{i}(\theta, \lambda, \delta)\right)
\end{aligned}
$$

Where, $M o$ is the seismic moment, $\rho$ is the density, $S(t)$ is the source time function, "*" denotes the convolution process and $A_{i}$ are coefficients determined by the source orientation and are given by:

$$
\begin{aligned}
& A_{1}(\theta, \lambda, \delta)=\sin 2 \theta \cos \lambda \sin \delta+0.5 \cos 2 \theta \sin \lambda \sin 2 \delta \\
& A_{2}(\theta, \lambda, \delta)=\cos \theta \cos \lambda \sin \delta-\sin \theta \sin \lambda \cos 2 \delta \\
& A_{3}(\theta, \lambda, \delta)=0.5 \sin \lambda \sin 2 \delta \\
& A_{4}(\theta, \lambda, \delta)=\cos 2 \theta \cos \lambda \sin \delta-0.5 \sin 2 \theta \sin \lambda \cos 2 \delta \\
& A_{5}(\theta, \lambda, \delta)=-\sin \theta \cos \lambda \sin \delta-\cos \theta \sin \lambda \cos 2 \delta
\end{aligned}
$$

where $\theta$ is station azimuth from the source minus fault strike, $\delta$ is the fault dip and $\lambda$ is fault rake. In this study,
Table 2. The initial velocity model used in this study.

\begin{tabular}{cccc}
\hline Depth $(\mathrm{km})$ & $V p(\mathrm{~km} / \mathrm{s})$ & $V s(\mathrm{~km} / \mathrm{s})$ & $\rho\left(\mathrm{g} / \mathrm{cm}^{3}\right)$ \\
\hline 0.0 & 5.00 & 3.00 & 2.45 \\
0.5 & 5.90 & 3.45 & 2.66 \\
15.0 & 6.60 & 3.85 & 2.83 \\
30.0 & 7.75 & 4.35 & 3.11 \\
\hline
\end{tabular}

triangular source time function and about 700 rays of different types and paths are used. For more details of the GRT technique, see Helmberger (1983).

The seismic source and propagation parameters are required to construct synthetic seismograms. We used the hypocentral parameters determined by the seismic network (Hi-net). The focal mechanisms are estimated in this study by inverting the $P$-wave polarity data we picked up manually (see Fig. 1). An average velocity model from a previous study (Zhao et al., 1992) is used as the initial model for this study. A surface layer with a thickness of $0.5 \mathrm{~km}$ and $P$-wave velocity of $5.0 \mathrm{~km} / \mathrm{s}$ is added at the top of the model for accounting for the high-frequency contents of local events. Table 2 shows details of the initial crustal model adopted in this study.

We developed an iterative technique to determine the velocity structure by cross-correlating the synthetics with the observed seismograms. For the mathematical formulation of the cross correlation process, let $\boldsymbol{u}_{\boldsymbol{k}}(\boldsymbol{t})$ denote the observed component $\boldsymbol{k}$ after the instrumental correction, $k$ can be vertical, radial or tangential component. $\boldsymbol{S}_{\boldsymbol{k}}(\boldsymbol{t})$ is the synthetic seismogram. For a lag time $\tau$, the cross-correlation coefficients $\boldsymbol{C}_{\boldsymbol{k}}(\tau)$ of observed and synthetic seismograms within the correlated window, $t_{1} \leq t \leq t_{2}$, can be expressed as:

$$
C_{k}(\tau)=\int_{t 1}^{t 2} u_{k}(t-\tau) S_{k}(t) d t
$$

For a given parameter, the cross-correlation coefficients $\boldsymbol{C}_{\boldsymbol{k}}(\tau)$ are calculated for the whole searching space. The parameter spaces are selected covering an appropriate range. This avoids the falling in local maxima that may be produced during the search. Table 3 shows the different search- 
Table 3. The searching parameters and the searching space.

\begin{tabular}{llll}
\hline & Searching parameter & Searching space & Search interval \\
\hline Source parameters & Source time function & $0.04-0.50 \mathrm{sec}$ & $0.02 \mathrm{sec}$ \\
& Strike & $0-360^{\circ}$ & $10^{\circ}$ \\
& Dip & $0-90^{\circ}$ & $10^{\circ}$ \\
& Slip & $0-90^{\circ}$ & $10^{\circ}$ \\
\hline Velocity model parameters & Surface layer thickness & $0.0-3.5 \mathrm{~km}$ & $0.5 \mathrm{~km}$ \\
& Surface layer velocity & $3.0-6.0 \mathrm{~km} / \mathrm{s}$ & $0.1 \mathrm{~km} / \mathrm{s}$ \\
& Conrad depth & $15.0-22.0 \mathrm{~km}$ & $1.0 \mathrm{~km}$ \\
& Upper crust velocity & $5.5-6.5 \mathrm{~km} / \mathrm{s}$ & $0.1 \mathrm{~km} / \mathrm{s}$ \\
& Moho depth & $29.0-36.0 \mathrm{~km}$ & $1.0 \mathrm{~km}$ \\
& Lower crust velocity & $6.5-7.1 \mathrm{~km} / \mathrm{s}$ & $0.1 \mathrm{~km} / \mathrm{s}$ \\
& Upper Mantle velocity & $7.3-8.0 \mathrm{~km} / \mathrm{s}$ & $0.1 \mathrm{~km} / \mathrm{s}$ \\
\hline
\end{tabular}

(a)

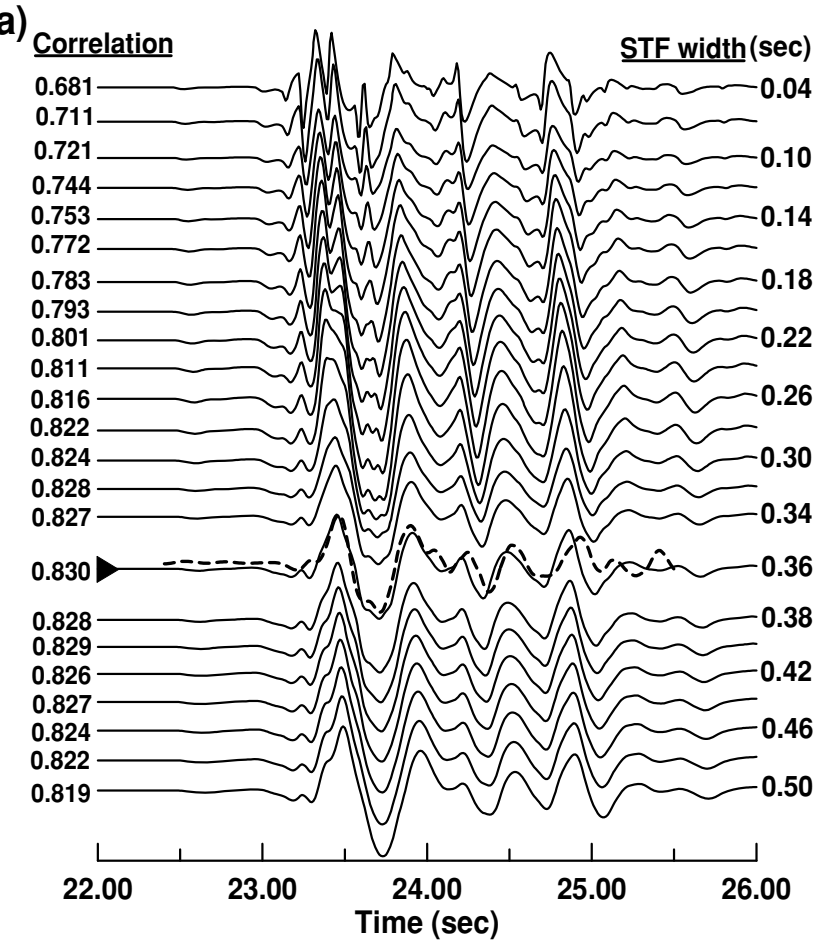

(b)

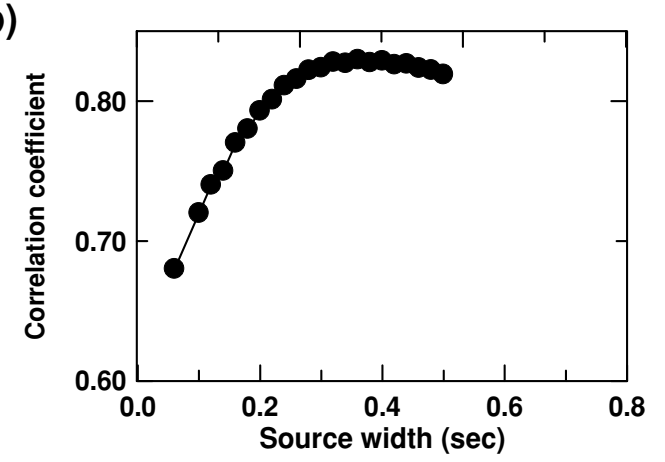

Fig. 2. Effect of source time function width on synthetic seismograms. (a) The solid-line traces show synthetic seismograms for different widths of a triangle-shape source time function (STF). The dashed lines show the observed seismogram for the path from Event 1 to station KAMH (see Fig. 1); its epicentral distance is $137 \mathrm{~km}$ and the focal depth is $12.4 \mathrm{~km}$. The STF width of each synthetic seismogram is shown on the right side. The maximum cross-correlation coefficient between the observed seismogram and each of the synthetic seismograms is shown on the left side. (b) Distribution of the cross-correlation coefficients with respect to the STF width (in second) adopted.

ing parameters and their corresponding searching space and intervals. The searching intervals are selected to be 0.02 sec, $10^{\circ}, 0.5-1.0 \mathrm{~km}$ and $0.1 \mathrm{~km} / \mathrm{s}$ for source time function, focal mechanism parameters, layer depth and layer velocity, respectively. The parameters are searched individually while keeping the adjacent parameters fixed. Starting with the parameter of the greater effect on synthetic, the maximum cross-correlation coefficient among the whole searching space yields the best parameter value. By using an appropriate starting model, the parameters are going to be solved in order of importance avoiding the misleading of using false parameters in the search.
To investigate the velocity structure in SW Japan, 29 paths from four events are used. The resulted velocity model is considered to be the average 1-D model between the source and the receiver. This 1-D model assumption is valid if velocity discontinuities (like the Conrad and the Moho) are generally flat and lateral velocity variations are small. According to the previous studies (Tani, 2002; Kudo and Yamaoka, 2003; Salah and Zhao, 2003), Biwa Lake (see Fig. 1(b)) has a considerably different velocity structure from that of the surrounding areas. Moreover, the crustal structure of SW Japan determined by Zhao et al. (1992) shows distinctive changes of the Conrad and Moho 
(a)

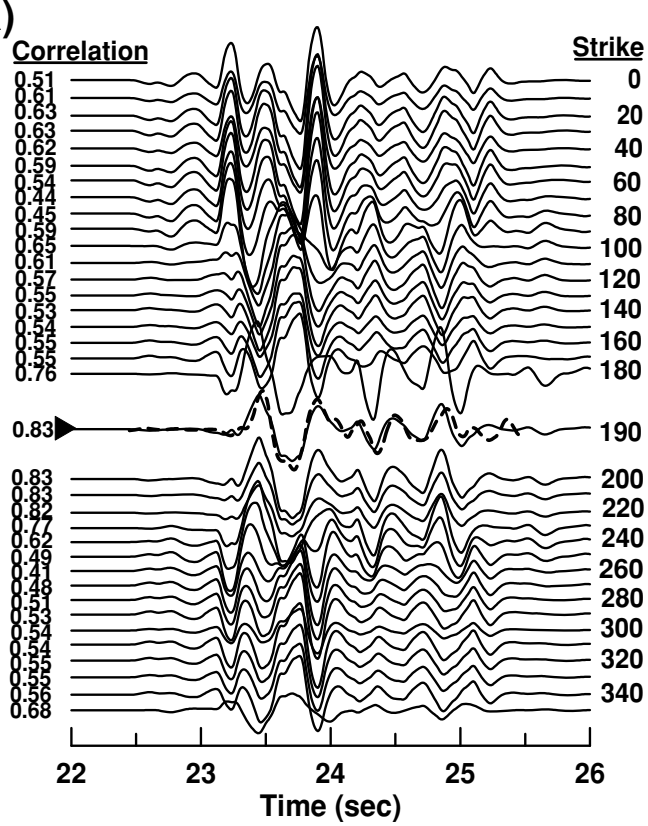

(c)

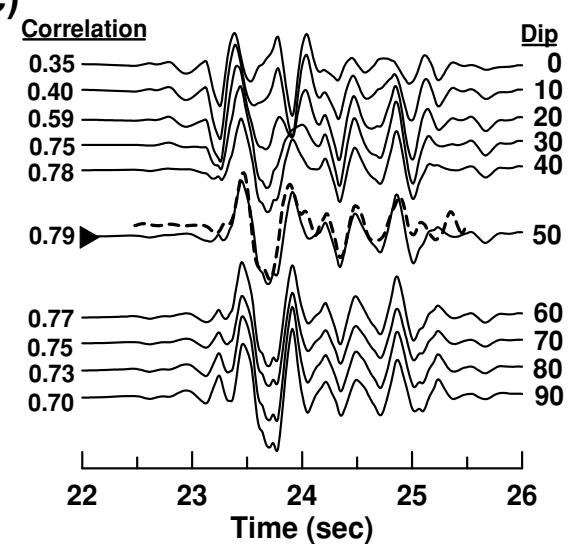

(e)

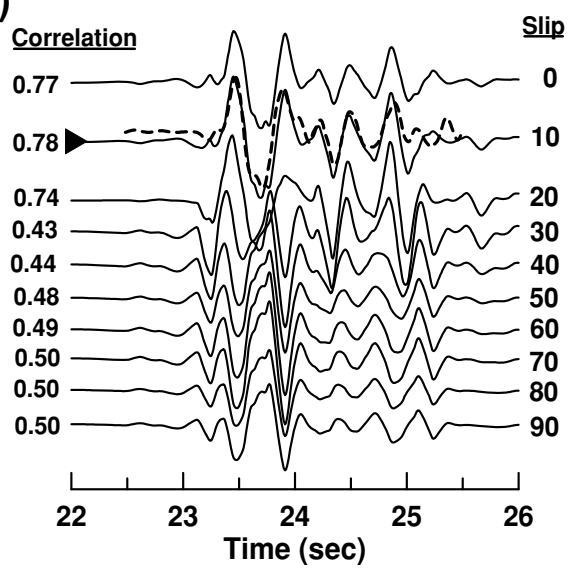

(b)

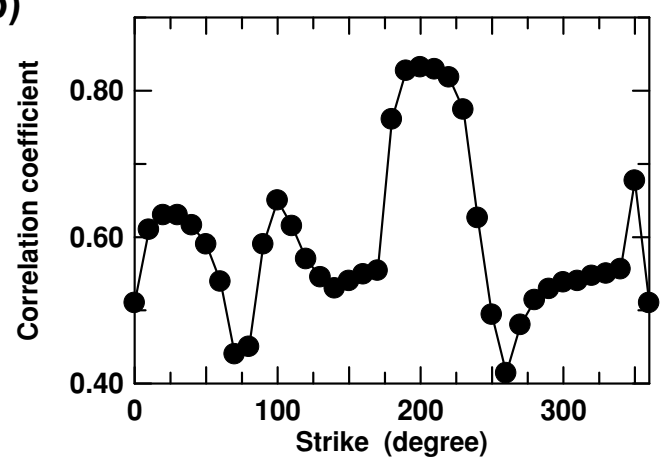

(d)

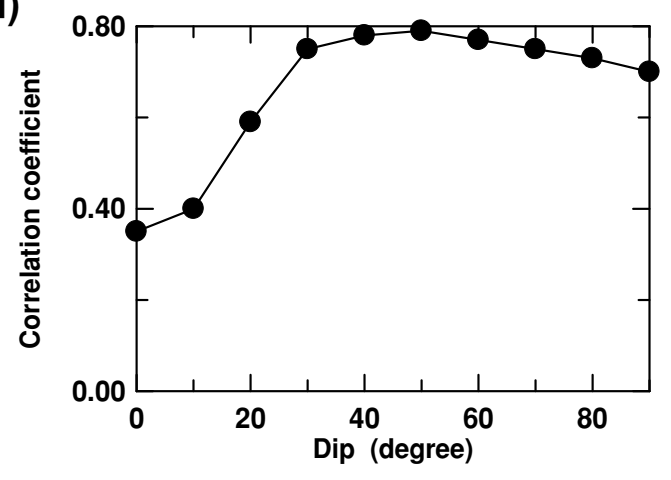

(f)

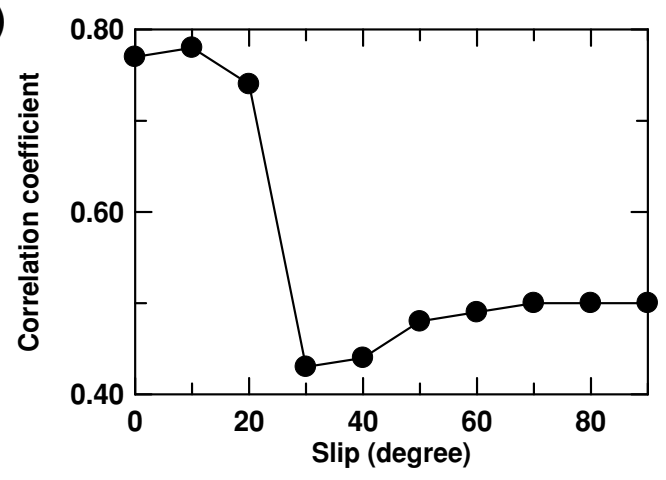

Fig. 3. Effect of fault plane solution on synthetic seismogram. Labels are the same as those of Fig. 2 but for the strike (a, b), dip (c, d) and slip (e, f).

depths in the present study area. Therefore, a single 1-D velocity model is not enough to model all the paths simultaneously. Hence, the above approach is applied to the individual paths to study the lateral variation of the main crustal discontinuities beneath the study area and the effect of Biwa Lake on the resulted models.

\section{Effects of Source Parameters on Synthetic Seis- mograms}

Here we select the path EV1-KAMH (see Fig. 1(b)) to describe the technique. Only the results for the verticalcomponent seismograms are shown. The epicentral distance of this path is $137 \mathrm{~km}$ and the azimuth is $257^{\circ}$. The effects of the source pulse width and focal mechanisms on 
(a)
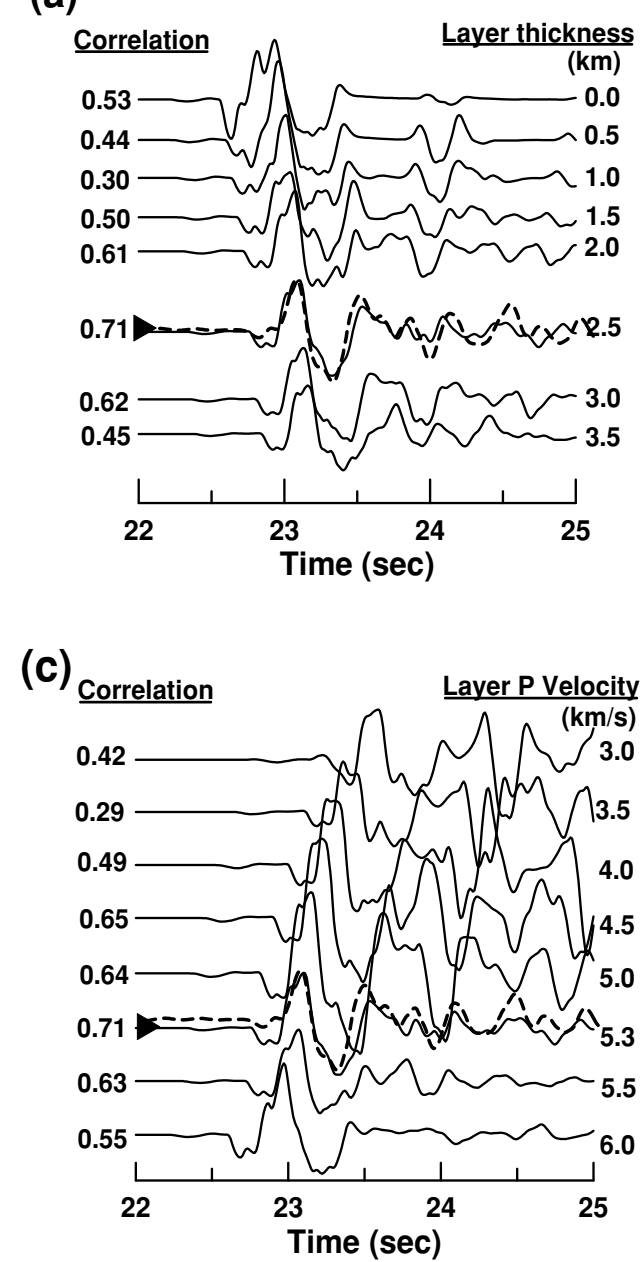

(b)

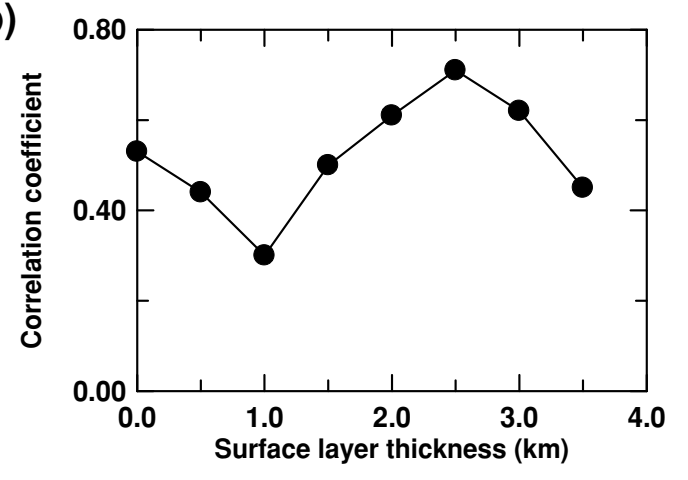

(d)

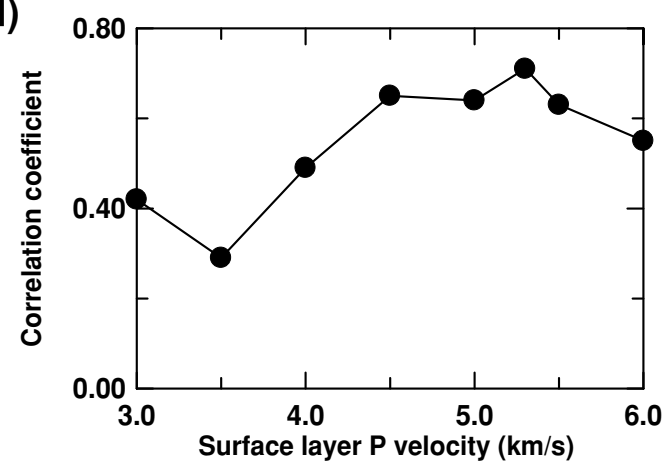

Fig. 4. Effect of surface layer on synthetic seismogram. The same as Fig. 3 but for the surface layer thickness (a, b) and the surface layer velocity (c, d).

the synthetics are firstly investigated to check the reliability of the technique before proceeding with the retrieval of the crustal velocity model.

\subsection{Source pulse width}

The Green's function that describes well the propagation path is convolved with an appropriate source pulse width, which is estimated by cross-correlating synthetics of different source widths with the observed record. We assume triangular source time functions having widths depending on the event magnitude and the epicentral distance. The approach seeks the pulse width that maximizes the crosscorrelation coefficient of the initial observed $P$-wave and synthetic traces. During this process, focal mechanism and velocity model are fixed. Figure 2(a) shows synthetic seismograms with different triangle pulse widths ranging from 0.04 to $0.5 \mathrm{sec}$ (solid traces) which are constructed and compared with the corresponding observed waveform (dashed trace). The cross-correlation coefficients for the synthetic and the observed waveforms are also shown in the figure. It is obvious that the dominant periods of the synthetics increase with the increasing pulse width. Figure 2(b) shows the distribution of the cross-correlation coefficients with respect to the source width, which leads to the best value of $0.36 \mathrm{sec}$ for the pulse width of the path EV1-KAMH. For events of small magnitudes, changes in pulse width are found for different epicentral distances, which is due to the effect of the attenuation factor $Q$ (Blair and Spathis, 1984; Ohtake, 1987; Langston, 2003). Accordingly, for the events used in this study, a variety of pulse width are tried to balance the width of the $P$-wave pulse against the high frequency contents of the waveform.

\subsection{Focal mechanism}

Here we study the sensitivity of the synthetic seismogram to the focal mechanism parameters. Following the same procedure, synthetic seismograms with different strike, dip and slip values are constructed (Figs. 3(a), 3(c) and 3(e)). The effect of each individual parameter of the focal mechanism is examined by fixing other parameters to their values estimated from the $P$-wave polarity inversion. The synthetics constructed with the focal mechanisms estimated from the $P$-wave polarity data show good agreement with the observed seismogram. This confirms the accuracy of the focal mechanism solution. The distribution of the crosscorrelation coefficients with respect to the strike is shown in Fig. 3(b). In general, the cross-correlation coefficients fluctuate in the entire parameter space. This indicates the sensitivity of the synthetic seismogram to the strike parameter. The maximum correlation is reached around the value $200^{\circ}$ that is close to the strike value estimated from the $P$ wave polarity data $\left(190^{\circ}\right)$. The dip parameter (Fig. 3(d)) 
(a)

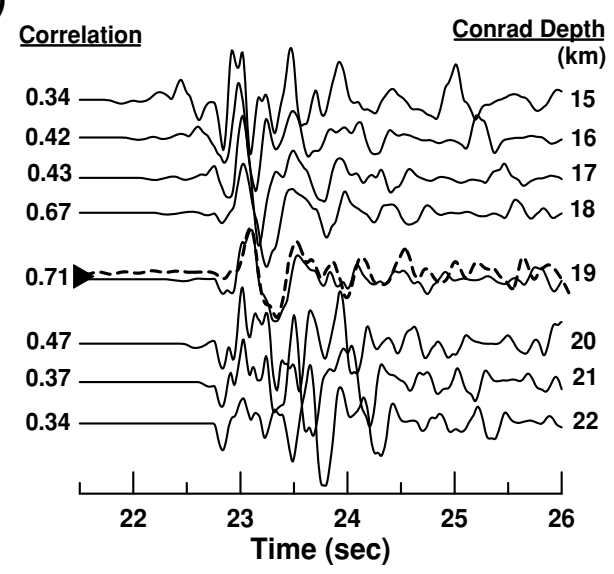

(c)

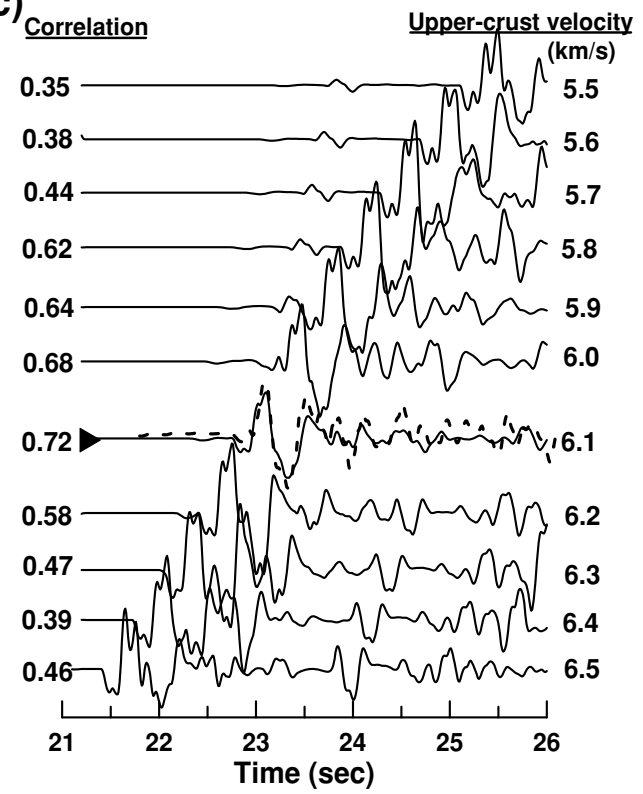

(b)

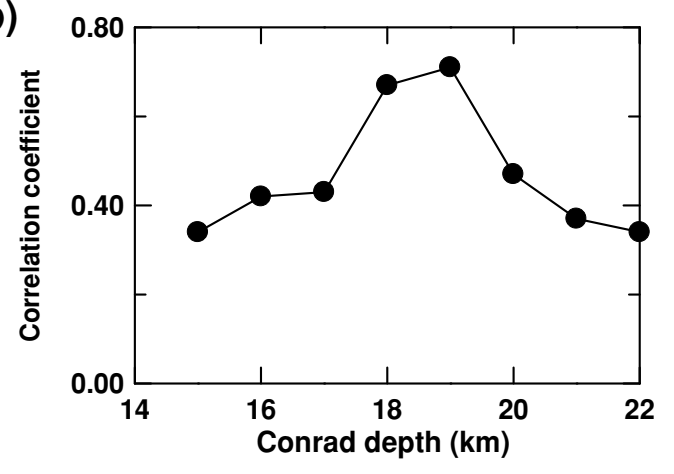

(d)

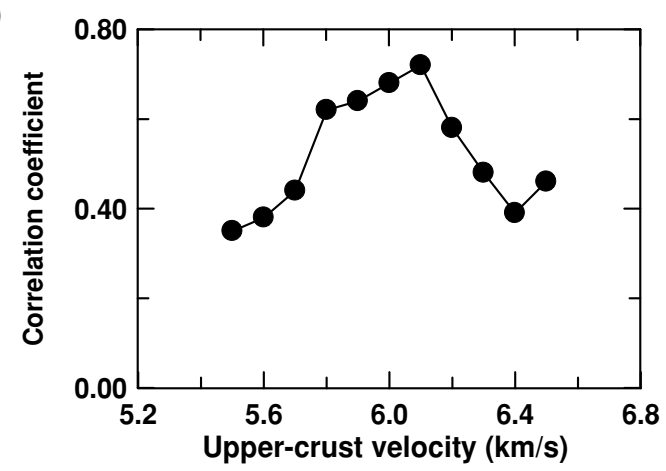

Fig. 5. Effect of the upper crust on synthetic seismogram. The same as Fig. 4 but for the Conrad depth (a, b) and the upper crust velocity (c, d).

has a broad range of maxima around the estimated value $\left(50^{\circ}\right)$, which reflects the weak effect of the dip parameter on synthetics. The slip parameter has a maximum correlation coefficient around the estimated slip value $\left(5^{\circ}\right)$ and has a sudden drop in correlation from $30^{\circ}$ (Fig. 3(f)). However, the cross-correlation coefficient for a particular parameter may change if other parameters are not accurately selected. Hence, without additional information on the focal mechanism it would be hard to choose a correct solution based solely on the maximum cross-correlation coefficient for one observed seismogram. The waveform similarity can be reached for different mechanisms and hypocentral parameters (Dreger, 1993).

\section{Waveform Modelling for Crustal Structure}

Using the estimated source parameters, we examine the crustal model through the search for the maximum correlations over the parameter spaces of the velocity model. Our main target is to estimate the best velocity model parameters and study their effects on synthetic seismograms. This is completed by identifying the global maxima of the cross- correlation coefficients.

\subsection{Surface layer}

We examine the effect of a sedimentary layer of small thickness and lower velocity on the top of the crust. A wide range of its thickness $(0.0-3.5 \mathrm{~km})$ and its $P$-wave velocity $(V p)(3.0-6.0 \mathrm{~km} / \mathrm{s})$ is examined. The initial values of the Moho and Conrad depths are kept fixed (Table 2). Slight reductions of the surface reflected phase travel times and significant changes in synthetics occur when increasing the layer velocity. The maximization of the cross-correlation coefficients yields a solution of $2.5 \mathrm{~km}$ for the surface layer thickness (Fig. 4(b)) and $5.3 \mathrm{~km} / \mathrm{s}$ for its $V p$ (Fig. 4(d)). For both the layer thickness and layer velocity the cross correlations show a broad distribution in the whole parameter space, which makes the identification of this layer less certain in many cases. For a relatively thick layer, the crosscorrelation coefficient distribution would have a clear maxima and so the detection of the surface layer will be feasible.

\subsection{Upper crust}

Synthetic seismograms with different Conrad depths and upper-crust velocities are constructed (Figs. 5(a) and 5(c)). 
(a)

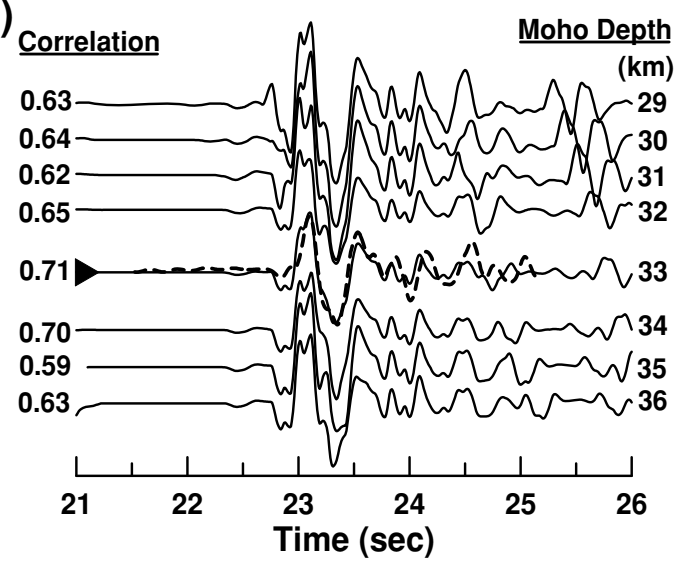

(c)

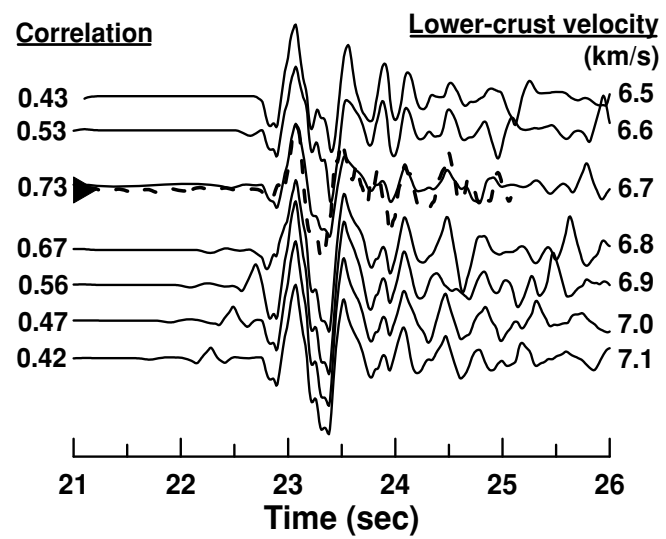

(e)

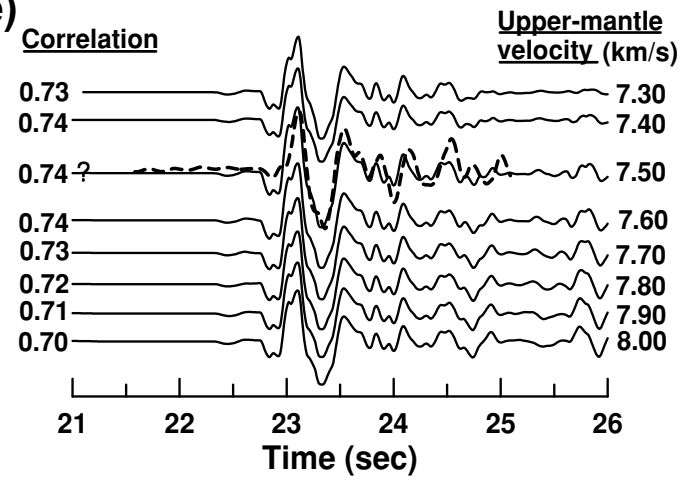

(b)

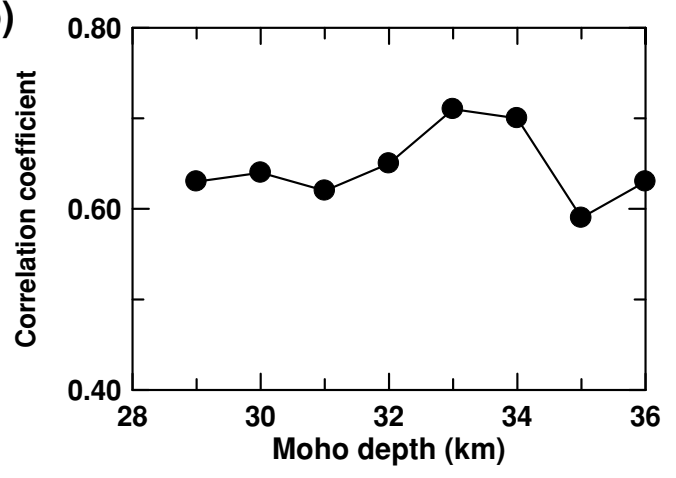

(d)

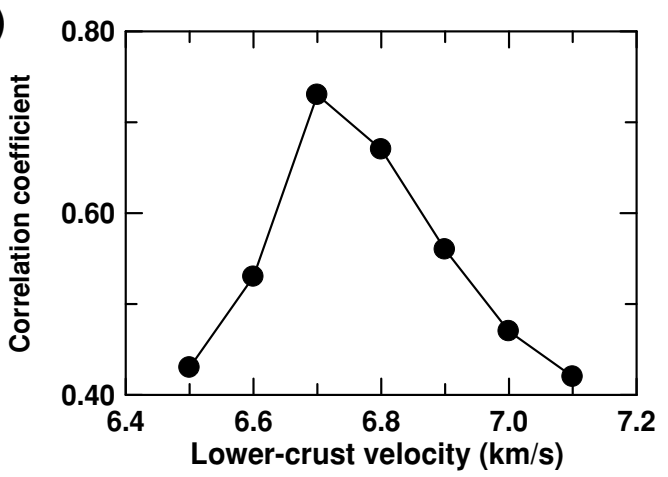

(f)

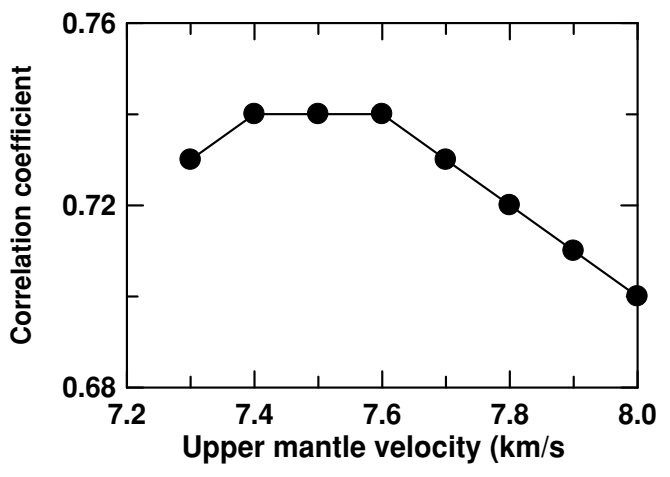

Fig. 6. Effect of the lower crust and the upper mantle on synthetic seismogram. The same as Fig. 4 but for the Moho depth (a, b), the lower crust velocity (c, d) and the upper mantle velocity (e, f).

The Conrad depth ranges from 15 to $22 \mathrm{~km}$ and the uppercrust velocity ranges from 5.5 to $6.5 \mathrm{~km} / \mathrm{s}$. The Conrad depth has a strong effect on synthetic seismograms (Fig. 5(b)). For different values of the upper-crust velocity, significant delays of the whole wave train are visible (Fig. 5(c)). These delays affect crucially the matching of the observed and synthetic travel time values. Figures 5(b) and 5(d) show the distribution of the cross-correlation coefficients with respect to the Conrad depth and the upper-crust velocity, respectively. For this path (EV1-KAMH) the best Conrad depth is found to be $19 \mathrm{~km}$ and the best upper-crust velocity is $6.1 \mathrm{~km} / \mathrm{s}$.

\subsection{Lower crust}

Synthetic seismograms with different values of lowercrust velocity and Moho depth are constructed (Figs. 6(a) and 6(c)). For the Moho depth, the maximum cross- correlation coefficient (Fig. 6(b)) yields a value of $33.0 \mathrm{~km}$, whereas $6.7 \mathrm{~km} / \mathrm{s}$ is the best value for the lower-crust velocity (Fig. 6(d)). Significant delays in the Moho refracted phases (i.e. Pn) with decreasing velocity are also observed. The effect of the lower-crust velocity on the synthetic seismogram is much greater than that of the lower-crust thickness, which is clear from the cross correlation distributions (Figs. 6(b) and 6(d)). Therefore, the lower-crust velocity and thickness can be well resolved by the waveform modelling. However, for short distances, the Moho depth is found to be uncertain due to the sparsely recorded Pn phases.

\subsection{Uppermost mantle}

For the synthetics with different uppermost mantle velocities (Fig. 6(e)), no significant changes or phase delays are observed. The synthetics are similar except for some later 
Table 4. Information on the paths studied.

\begin{tabular}{|c|c|c|c|c|c|c|c|}
\hline Path & Event & Station & $\Delta(\mathrm{km})$ & $\mathrm{Az}\left({ }^{\circ}\right)$ & Conrad $(\mathrm{km})$ & Moho (km) & Type \\
\hline 1 & Event 1 & TRGH & 41 & 312 & 16.3 & $\mathrm{NC}^{*}$ & Non-Biwa \\
\hline 2 & & $\mathrm{HNOH}$ & 47 & 192 & 16.2 & $\mathrm{NC}^{*}$ & Non-Biwa \\
\hline 3 & & OTUH & 48 & 252 & 15.0 & $\mathrm{NC}^{*}$ & Biwa \\
\hline 4 & & OBMH & 59 & 278 & $\mathrm{NC}^{*}$ & $\mathrm{NC}^{*}$ & Biwa \\
\hline 5 & & SGRH & 66 & 207 & 15.3 & 27.3 & Non-Biwa \\
\hline 6 & & OTAH & 69 & 335 & 17.0 & 26.1 & Non-Biwa \\
\hline 7 & & MYMH & 75 & 260 & 15.0 & $\mathrm{NC}^{*}$ & Biwa \\
\hline 8 & & EIHH & 79 & 359 & 14.8 & 28.0 & Non-Biwa \\
\hline 9 & & KAMH & 137 & 257 & 19.0 & 33.0 & $\sim$ Non-Biwa \\
\hline 10 & Event 2 & SGRH & 40 & 99 & 17.5 & $\sim 29.0$ & Non-Biwa \\
\hline 11 & & $\mathrm{HNOH}$ & 61 & 84 & 17.0 & 28.8 & Non-Biwa \\
\hline 12 & & OBMH & 61 & 11 & 16.8 & 30.3 & Non-Biwa \\
\hline 13 & & KAMH & 66 & 288 & 15.7 & 28.5 & Non-Biwa \\
\hline 14 & & TAGH & 78 & 62 & 18.0 & 30.0 & Biwa \\
\hline 15 & & IZSH & 90 & 312 & 19.0 & 33.0 & Non-Biwa \\
\hline 16 & Event 3 & EIHH & 22 & 306 & 16.2 & $\mathrm{NC}^{*}$ & Non-Biwa \\
\hline 17 & & $\mathrm{NEOH}$ & 38 & 112 & 17.1 & $\mathrm{NC}^{*}$ & Non-Biwa \\
\hline 18 & & OTAH & 46 & 266 & 16.8 & 27.3 & Non-Biwa \\
\hline 19 & & TAGH & 84 & 192 & 17.1 & 28.1 & Non-Biwa \\
\hline 20 & Event 4 & OTUH & 16 & 214 & 17.5 & $\mathrm{NC}^{*}$ & Non-Biwa \\
\hline 21 & & TRGH & 30 & 10 & 18.4 & $\sim 29.0$ & Non-Biwa \\
\hline 22 & & TAGH & 38 & 112 & 19.0 & $\sim 29.0$ & Biwa \\
\hline 23 & & MYMH & 40 & 253 & 16.0 & $\mathrm{NC}^{*}$ & Non-Biwa \\
\hline 24 & & $\mathrm{HNOH}$ & 52 & 149 & 18.0 & 31.0 & Biwa \\
\hline 25 & & SGRH & 58 & 174 & 18.5 & 30.0 & Biwa \\
\hline 26 & & OTAH & 64 & 6 & 17.0 & 28.5 & Non-Biwa \\
\hline 27 & & HMAH & 67 & 98 & 16.2 & 27.2 & Biwa \\
\hline 28 & & IZSH & 101 & 275 & 19.7 & 32.0 & Non-Biwa \\
\hline 29 & & KAMH & 102 & 253 & 19.4 & 33.4 & Non-Biwa \\
\hline
\end{tabular}

${ }^{*} \mathrm{NC}$ : Depth not determined because the ray path is short or the discontinuity is unclear.

phases. No best value of the cross-correlation coefficients is found. Instead, a flat maxima for the velocities of 7.4$7.6 \mathrm{~km} / \mathrm{s}$ is observed (Fig. 6(f)). Therefore, the effect of the upper mantle velocity is small for this range of epicentral distance.

Consequently, only the thickness and velocity of the upper and lower crust can be constrained for the path EV1KAMH by using the current approach. In the next section, modelling results of many other paths are shown.

\section{Results}

A total of 29 paths are modelled in this study (see Fig. 1 and Table 4). Because these paths sample lateral heterogeneous regions, we could not explain them by a single 1-D model. Instead, each path is studied individually by searching for the best 1-D model matching the observed and synthetic traces. The lateral variation of the crustal structure can be estimated by examining the resulted 1-D models for the 29 paths. The effects of Biwa Lake on the resulted models are examined by studying the paths passing through (Biwa paths) and outside the lake (non-Biwa paths).

In the following, we describe the different paths in detail with the corresponding waveform modelling results and the resulted velocity models.

\subsection{Event 1 paths}

We investigated nine paths from event 1; three of which pass through Biwa Lake (see Fig. 1). Figure 7 shows the record section of the vertical-component seismograms of this event reduced by $6.1 \mathrm{~km} / \mathrm{s}$. We observe relatively clear onsets of Biwa paths as compared with that of the non-Biwa paths. Slight delays of the wave trains are also visible for stations SGRH and OTAH.

Examples of the waveform modelling results are shown in Fig. 8. For the distance range $(48-137 \mathrm{~km})$ of the nine paths, a good matching is achieved especially for the vertical components. For the radial components, the correlations are slightly lower, which reflects the complexity of the crustal structure near the station (Savage et al., 2003). The delay in the path EV1-OTAH is modelled by a surface layer with a thickness of $3.5 \mathrm{~km}$ and $V p$ of $5.0 \mathrm{~km} / \mathrm{s}$. For the station SGRH, a surface layer of $0.4 \mathrm{~km}$ thick with $V p$ of $4.9 \mathrm{~km} / \mathrm{s}$ and an upper crust velocity of $6.05 \mathrm{~km} / \mathrm{s}$ lead to a good match of the arrival times. The resulted crustal models for these paths are shown in Fig. 9. The Conrad 


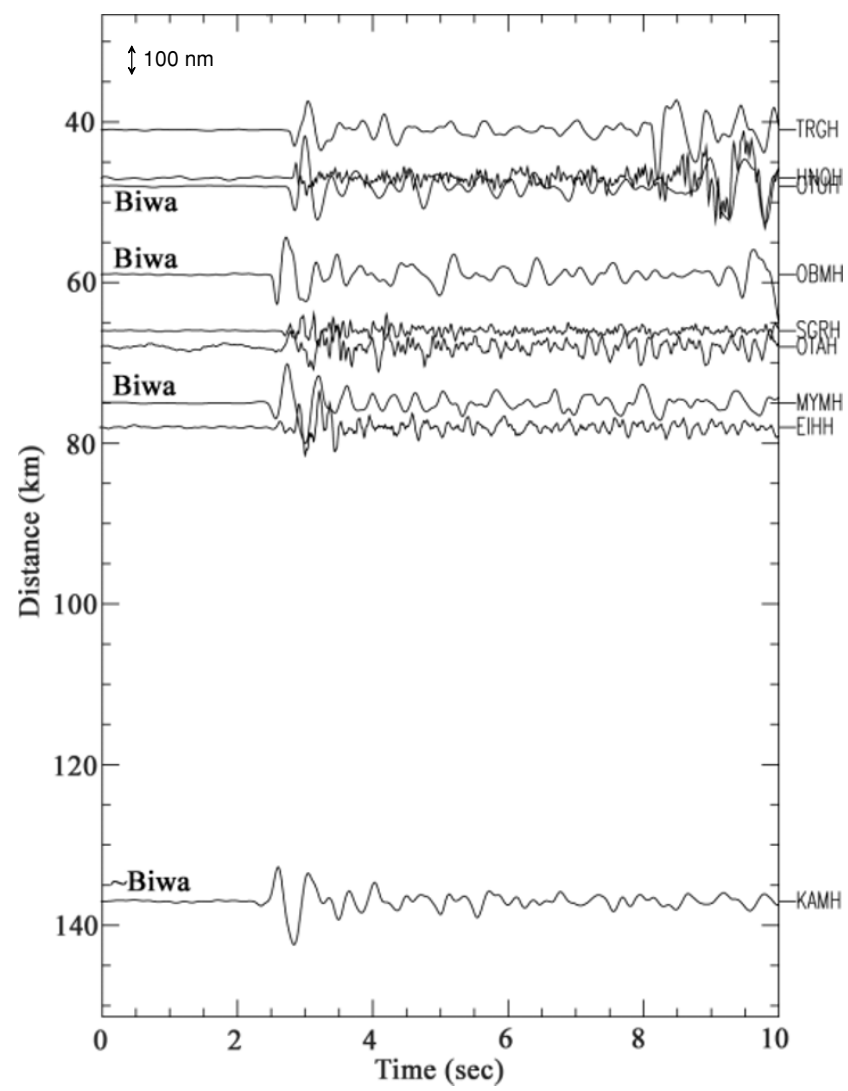

Fig. 7. Record section of the vertical-component observed seismograms of event 1 reduced by $6.1 \mathrm{~km} / \mathrm{s}$.

and Moho depths are different for the different paths. This variation of the velocity models reflects the complexity of the crustal structure in and around Biwa Lake. For the nonBiwa paths, the Conrad depth ranges from 15.8 to $17.0 \mathrm{~km}$ and the Moho depth ranges from 26 to $28 \mathrm{~km}$. The two paths, EV1-OUTH and EV1-MYMH, have nearly the same azimuth and show similar results. However, the path EV1$\mathrm{KAMH}$ is in the same azimuth range but shows a deeper Moho $(33.0 \mathrm{~km})$.

\subsection{Event 2 paths}

Event 2 has the smallest magnitude (M2.4) among the four events used in this study. Its paths cover the western part of the study area. Six paths are modelled for this event including one Biwa path. Figure 10 shows the reduced record section of this event. The path EV2-KAMH $(\Delta=65$ $\mathrm{km})$ shows a strong first $P$-wave onset. A distinctive delay of the wave arrivals is clearly visible for the path EV2OBMH (see Fig. 10). Examples of the waveform modelling results of this event are shown in Fig. 11. The waveform modelling yields good match between the observed and synthetic waveforms. The large $P$ pulse of the path EV2KAMH is successfully modelled by a surface layer of $V p=$ $4.5 \mathrm{~km} / \mathrm{s}$ and $0.5 \mathrm{~km}$ thickness. The delay at station $\mathrm{OBMH}$ is simulated by a thick surface layer $(3.5 \mathrm{~km})$ with $V p$ of $4.8 \mathrm{~km} / \mathrm{s}$. The maximum Conrad and Moho depths for this event are found to be 19 and $33 \mathrm{~km}$, respectively, for the path to station IZSH. For other non-Biwa paths, the average Conrad and Moho depths are 16.8 and $29.2 \mathrm{~km}$, respectively (see Fig. 12).

\section{Event 1 paths}

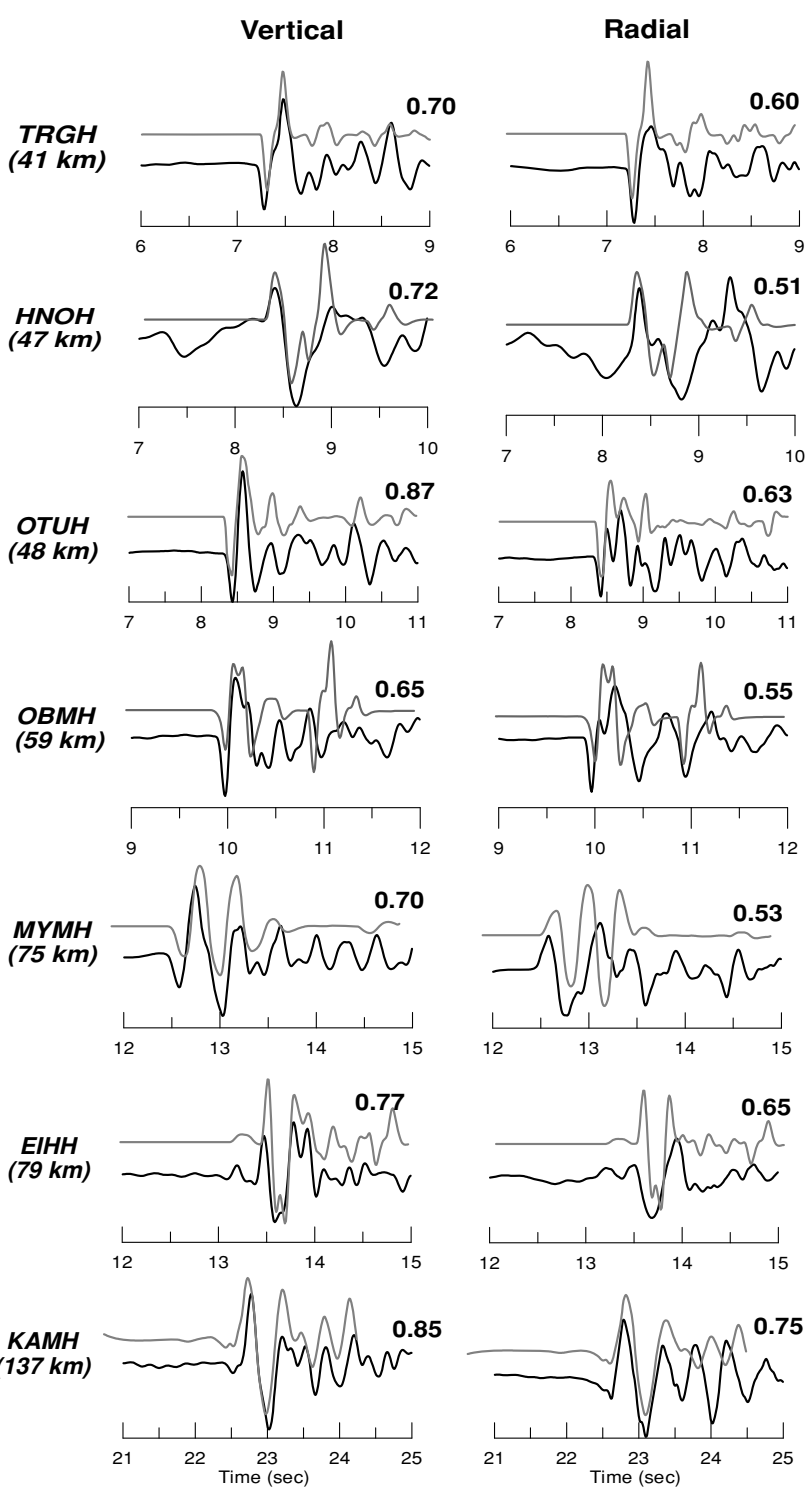

Fig. 8. Waveform modelling results for event 1 paths. Vertical and Radial components are shown in pairs. Each panel shows a comparison between the synthetic waveform (gray) and the observed waveform (black). The epicentral distance and the maximum correlation coefficient are shown to the left and right of each panel, respectively.

\subsection{Event 3 paths}

Event 3 is the shallowest $(9.4 \mathrm{~km})$ and the biggest event (M3.6) used in this study. For this event, four paths are successfully modelled which pass through the northern part of the study area. Figure 13 shows the reduced record section of this event. No distinctive arrival delays are observed. The station OTAH (northward near the coast) shows the strongest onset. Examples of the waveform modelling results are shown in Fig. 14. A good observed-synthetic matching is achieved. The large onset at station OTAH is modelled by a surface layer with a thickness of $2.2 \mathrm{~km}$ and $V p$ of $4.5 \mathrm{~km} / \mathrm{s}$. The average Conrad and Moho depths for these paths are 16.9 and $28.3 \mathrm{~km}$, respectively. The resulted velocity models (Fig. 15) are similar for all paths, suggesting a relatively simple structure beneath the western part of the study area. 
(a)

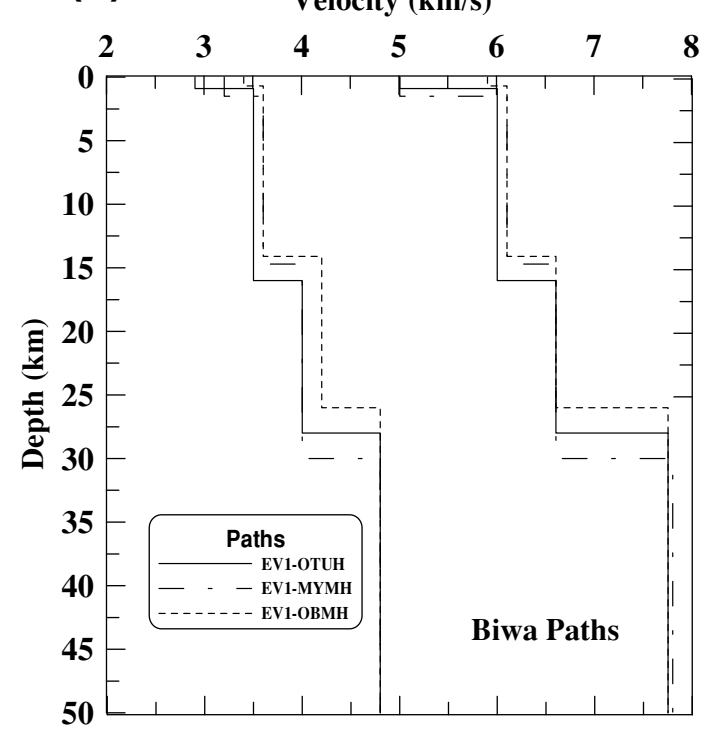

(b)

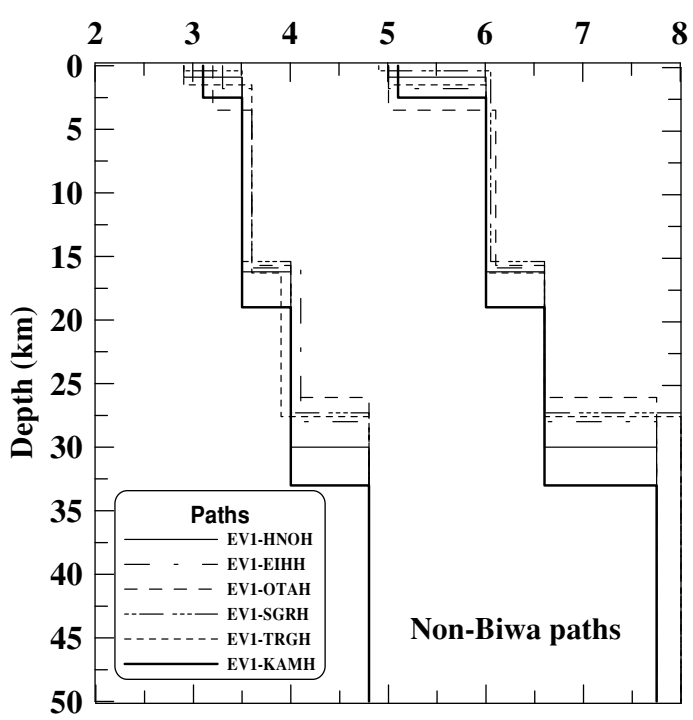

Fig. 9. Resulted velocity models of Biwa paths (a) and non-Biwa paths (b) of event 1 (see text for details).

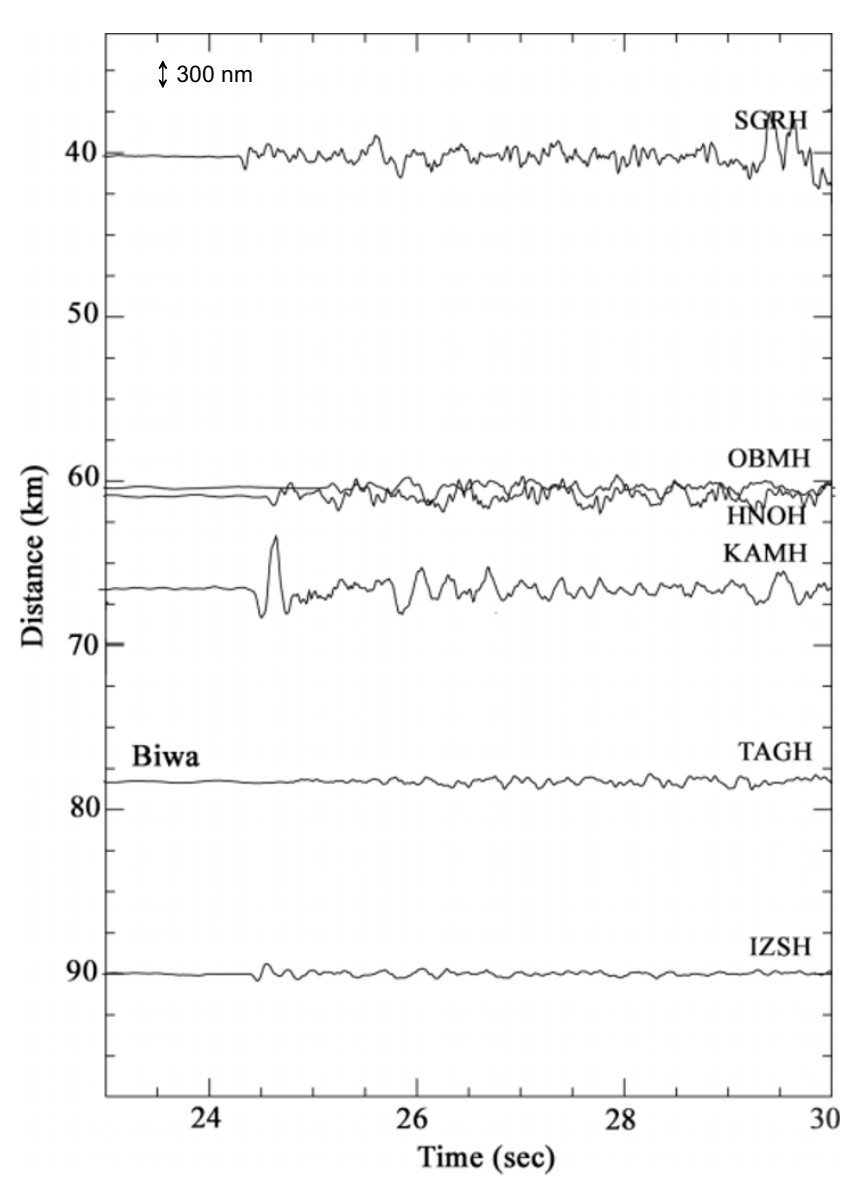

Fig. 10. Same as Fig. 7 but for event 2.

\subsection{Event 4 paths}

Ten paths are successfully modelled for this event, four of which are Biwa paths (see Fig. 1). The reduced record section of this event is shown in Fig. 16. A delay at station OTAH is observed as for the path EV1-OTAH. The wave-

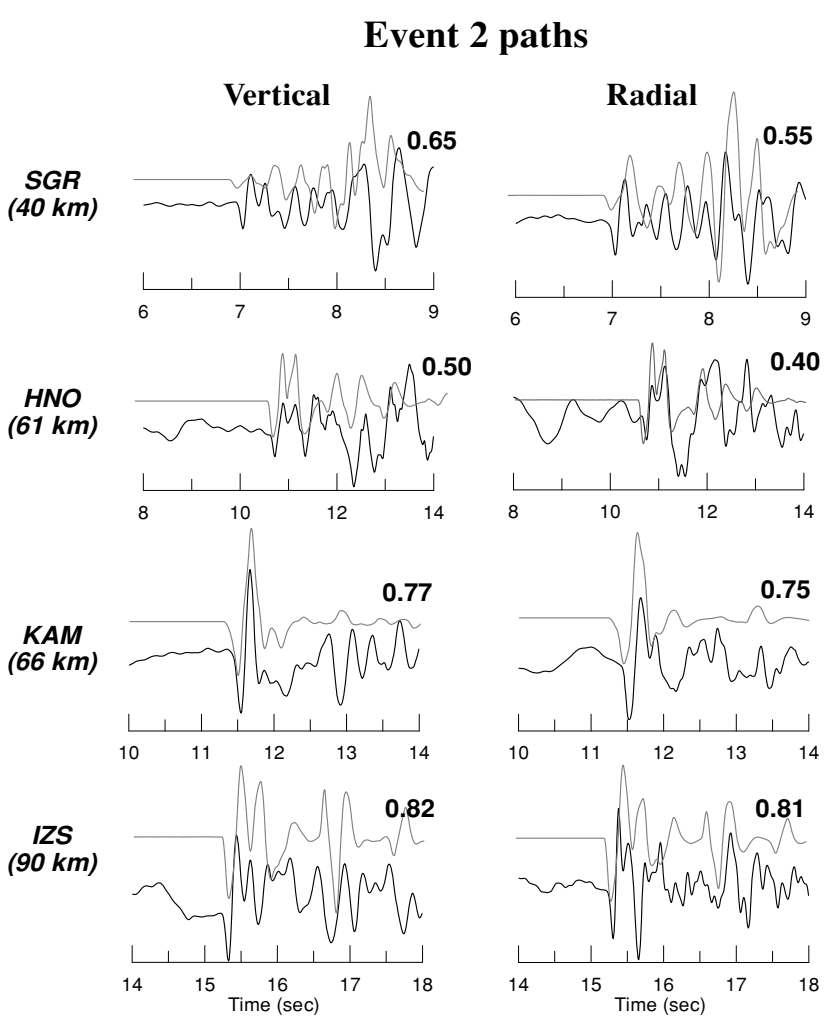

Fig. 11. Same as Fig. 8 but for event 2 .

form modellings (Fig. 17) show a good matching between the observed and synthetic traces. The resulted velocity models for these paths are shown in Fig. 18, which exhibit considerable changes in the crustal thickness. The delay at station OTAH is modelled by a surface layer of $3 \mathrm{~km}$ thick with $V p$ of $5.0 \mathrm{~km} / \mathrm{s}$. For stations KAMH and IZSH (to the west), the waveform modelling shows deep Conrad and Moho discontinuities (19.7 and $33.4 \mathrm{~km}$, respectively). 


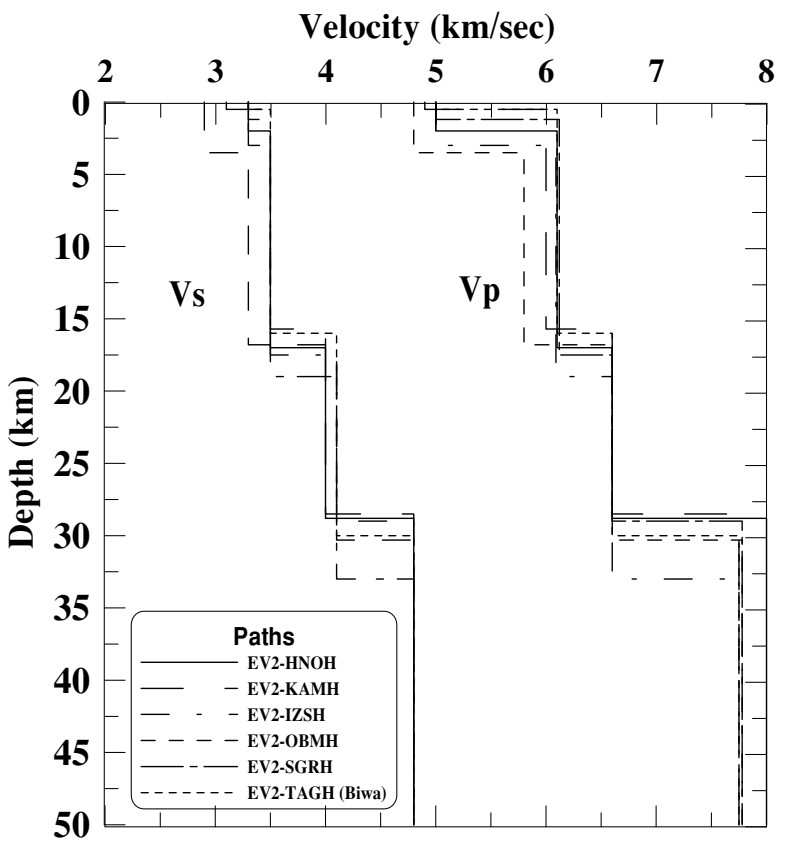

Fig. 12. The resulted velocity models of event 2 paths.

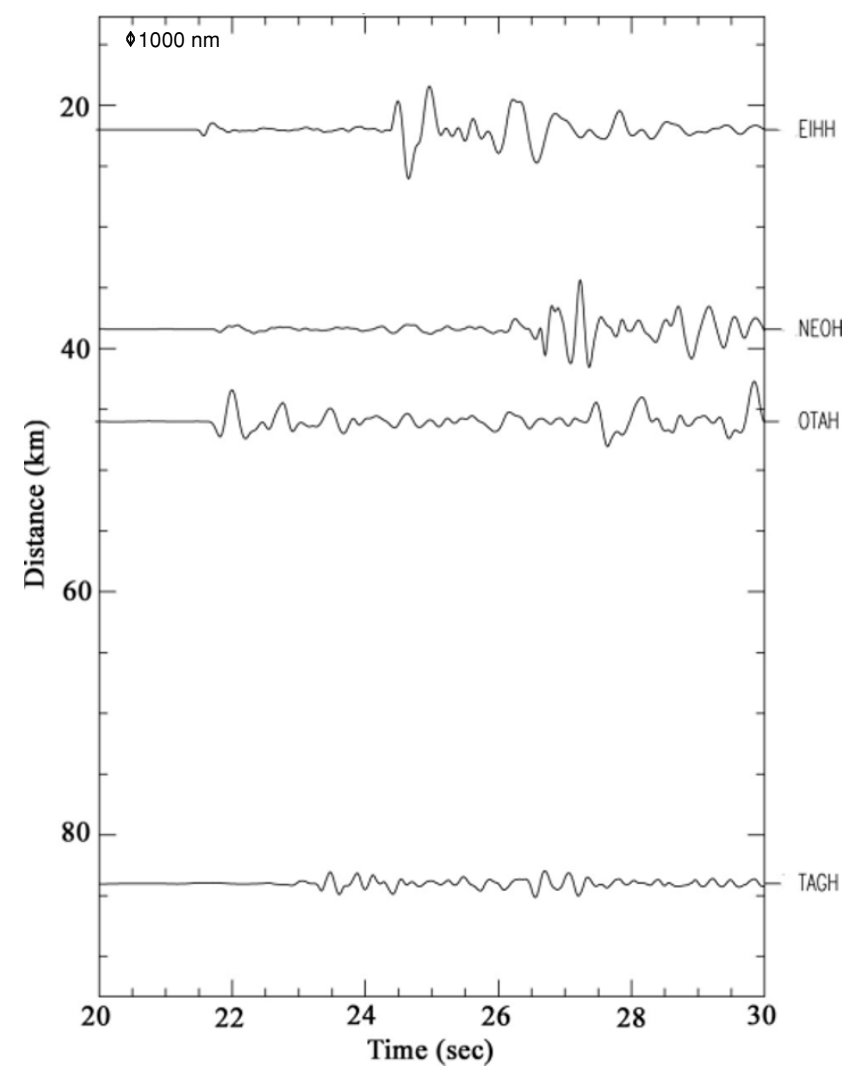

Fig. 13. Same as Fig. 10 but for event 3.

\subsection{Biwa paths}

The Biwa Lake depressions make the 1-D modellings a hard task. However, by modelling waveforms individually, average velocity models of the crust can be estimated. When examining the long path EV1-KAMH (see Fig. 1), we found that this path, crossing Biwa Lake, shows deep Conrad and Moho discontinuities. The ray distribution of
Event 3 paths

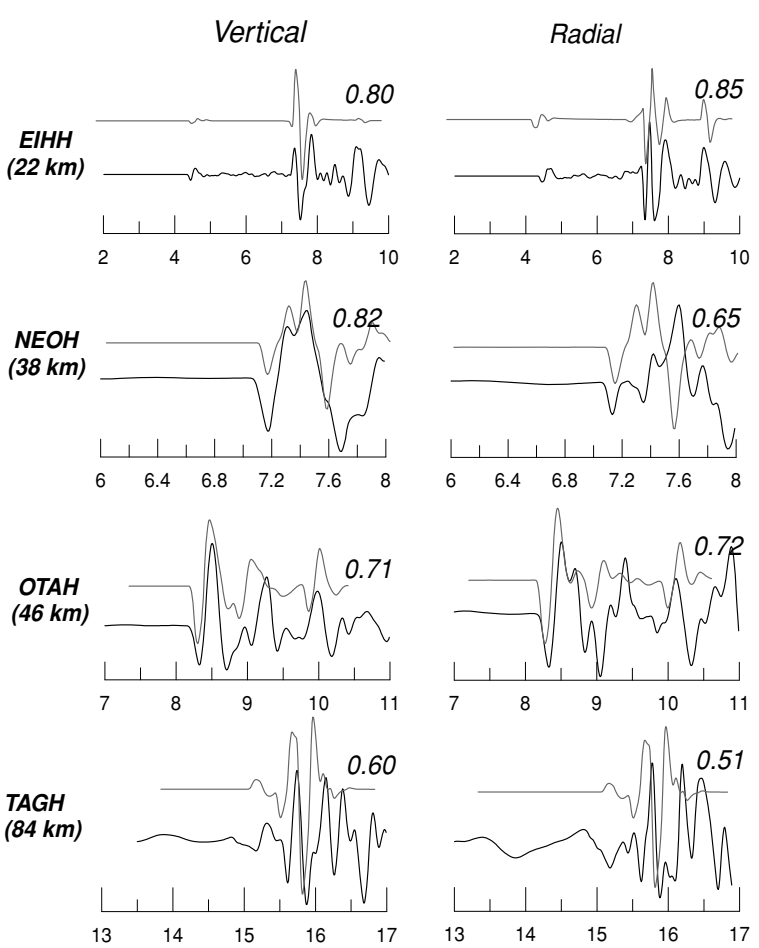

Fig. 14. Same as Fig. 11 but for event 3.

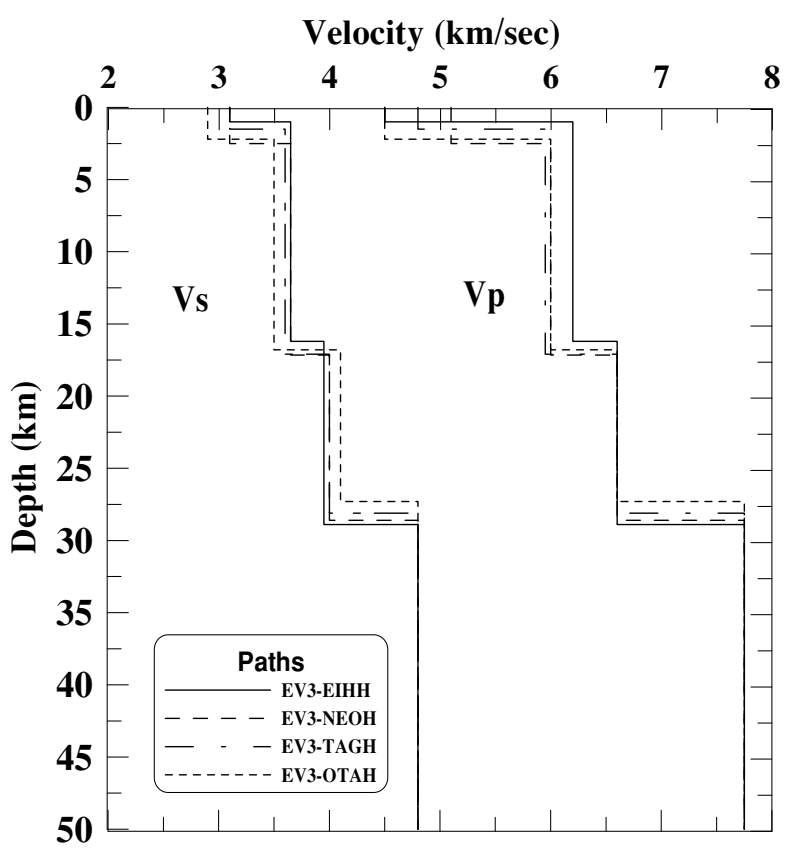

Fig. 15. The resulted velocity models of event 3 paths.

this path (Fig. 19) shows that the ray segments passing beneath Biwa Lake are shorter than that passing outside Biwa Lake. In addition, deeper Conrad and Moho discontinuities are also found for the non-Biwa paths to this specific station (EV2-KAMH and EV4-KAMH). This indicates that the Moho deepening occurs in the area near the station KAMH rather than Biwa Lake. Therefore, we consider this path a non-Biwa path due to the small effect of the lake. We con- 


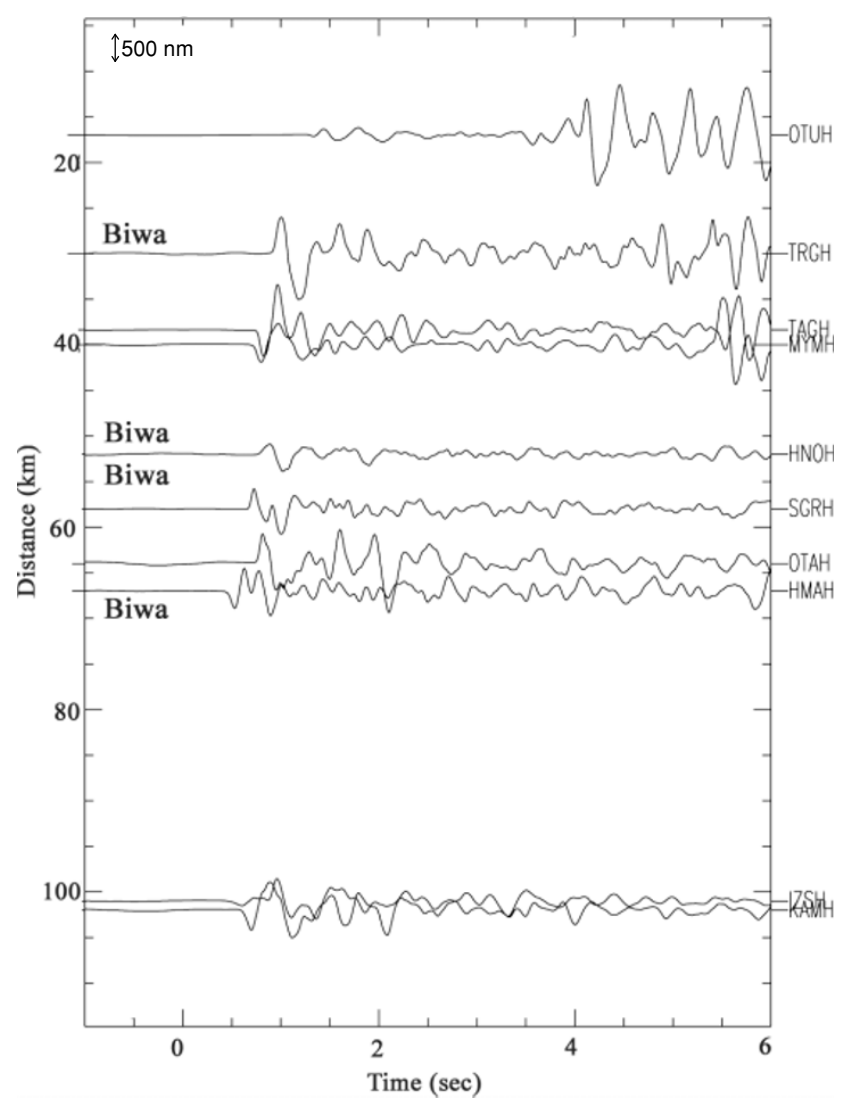

Fig. 16. Same as Fig. 13 but for event 4.

clude that the resulted velocity models mostly reflect the structure beneath this station (KAMH) with some effects of the rest portions of the path.

The eight Biwa paths modelled in this study yield different velocity models (Figs. 9(a), 12 and 18(a)). These models are considered to represent the structure beneath the recording stations involving some effects of Biwa Lake. If this is true, the resulted models for one common station should be similar. This is proved in the case of the nonBiwa paths that show very similar models (with few exceptions due to minor lateral changes, see Table 2). However, in the case of Biwa paths the effect of the lake is significant, which can be observed when studying the common station non-Biwa and Biwa paths.

The Conrad and Moho depths of the non-Biwa paths recorded by station SGRH (EV1-SGRH and EV2-SGRH) are of 15-17 km and 27-29 km, respectively, while its Biwa path results (EV4-SGRH) are 18.5 and $30.0 \mathrm{~km}$. The corresponding results of the non-Biwa paths for station $\mathrm{HNOH}$ (EV1-HNOH and EV2-HNOH) are 16.2-17.0 km and 25$29 \mathrm{~km}$, while its Biwa path (EV4-HNOH) results are 18 and $31 \mathrm{~km}$. The non-Biwa path results for station TAGH (EV3-TAGH) are 17 and $28 \mathrm{~km}$, while its Biwa paths results (EV2-TAGH and EV4-TAGH) are 18-19 and 29-30 $\mathrm{km}$. Results for other stations are not described here either because the paths are too short to well sample the structure or they have no corresponding paths to compare with.

From these results, we can see that Biwa Lake always causes the deepening of the Conrad and Moho by $1-3 \mathrm{~km}$. This suggests that the upper and lower crusts beneath Biwa

\section{Event 4 Paths}

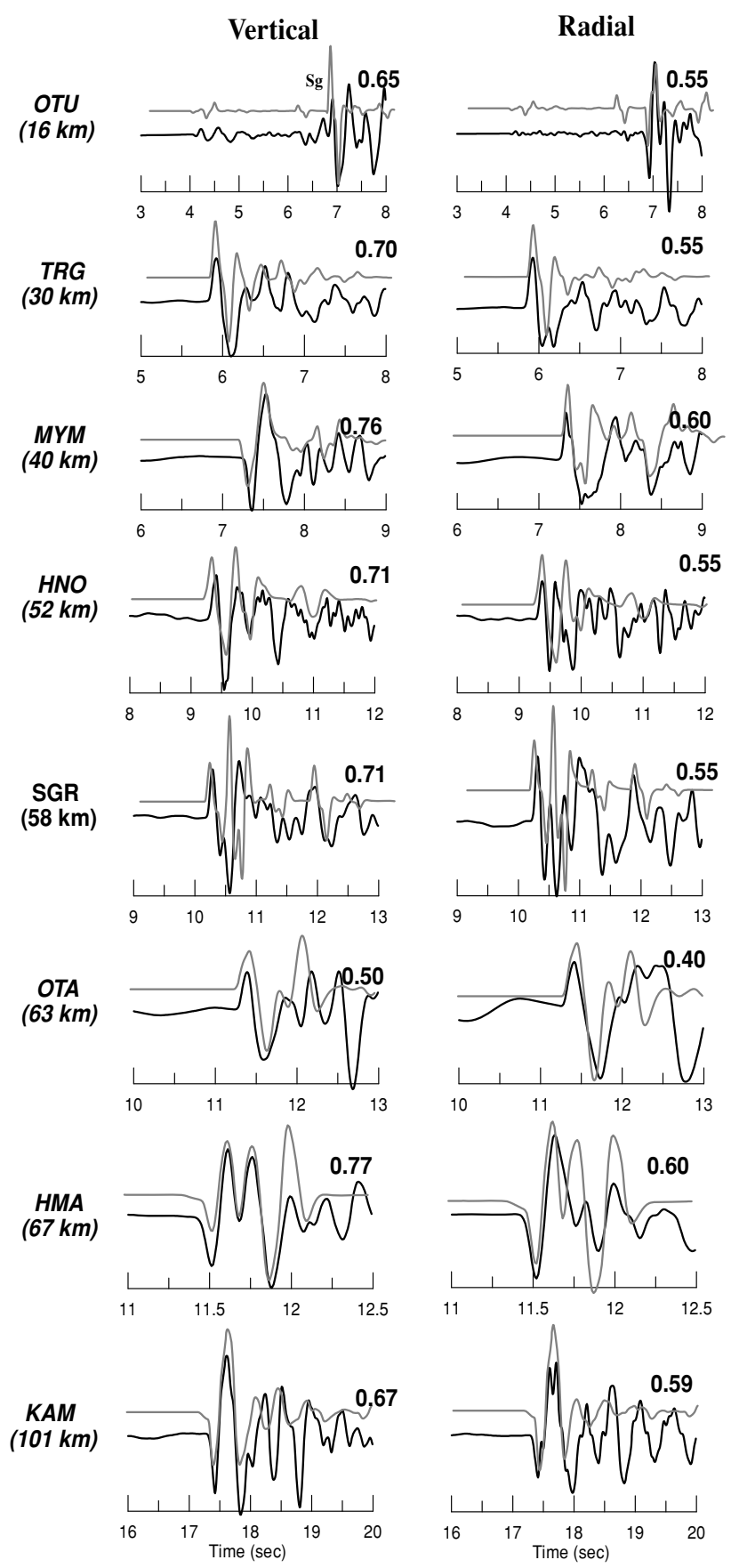

Fig. 17. Same as Fig. 14 but for event 4.

Lake are thicker than those of the surrounding areas.

The waveform modelling for the Biwa paths does not show any anomalous features except for clear early arrivals for the path EV4-HMAH. This path is modelled by a surface layer with a thickness of $0.5 \mathrm{~km}$ and $V p$ of $5.0 \mathrm{~km} / \mathrm{s}$. In general, the modellings are successful to obtain good match with the observations for most of the Biwa paths.

\section{Discussion and Conclusions}

The GRT technique is proven to be very efficient for retrieving the crustal velocity structure from local and regional waveforms. A number of tests were performed to 
(a)

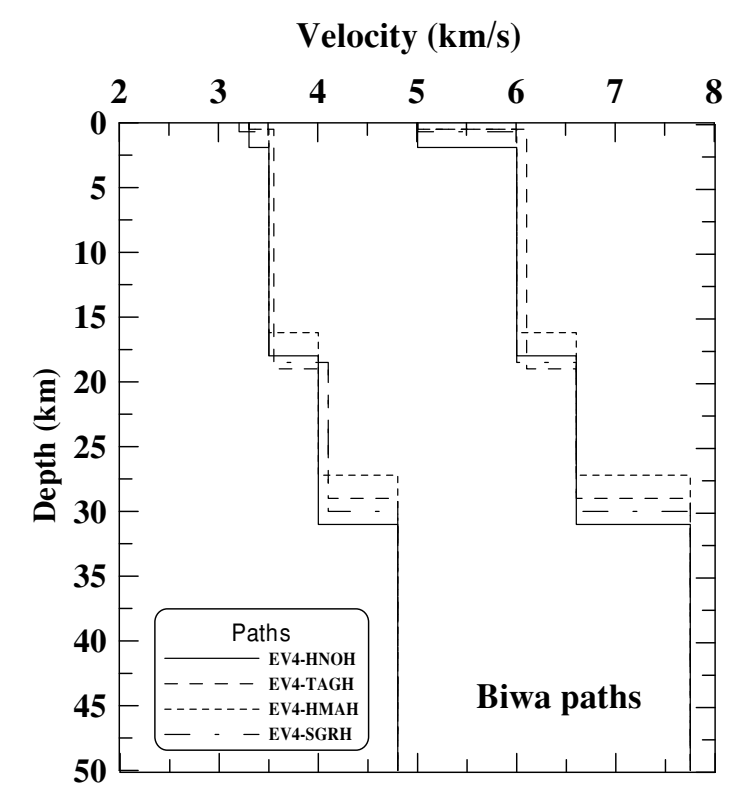

(b)

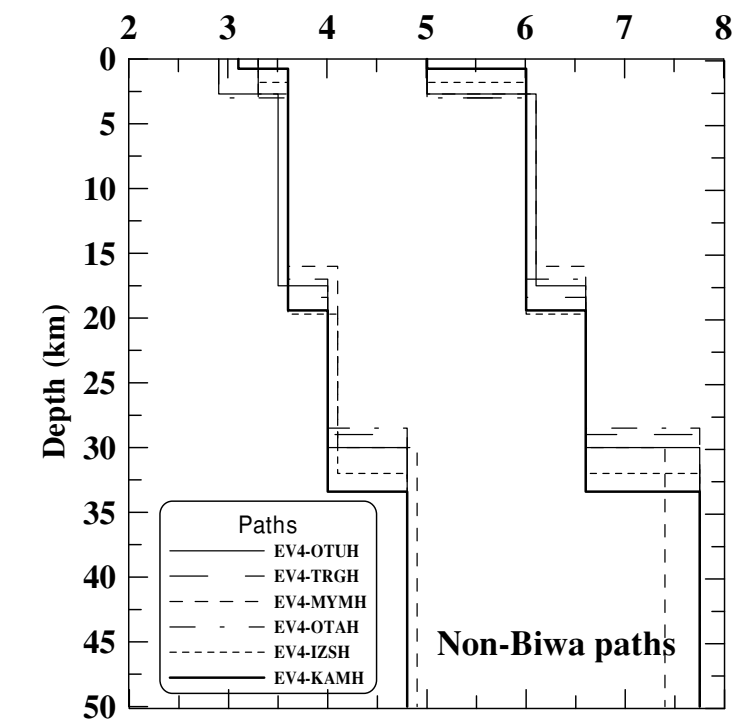

Fig. 18. Resulted velocity models of Biwa paths (a) and non-Biwa paths (b) of event 4.

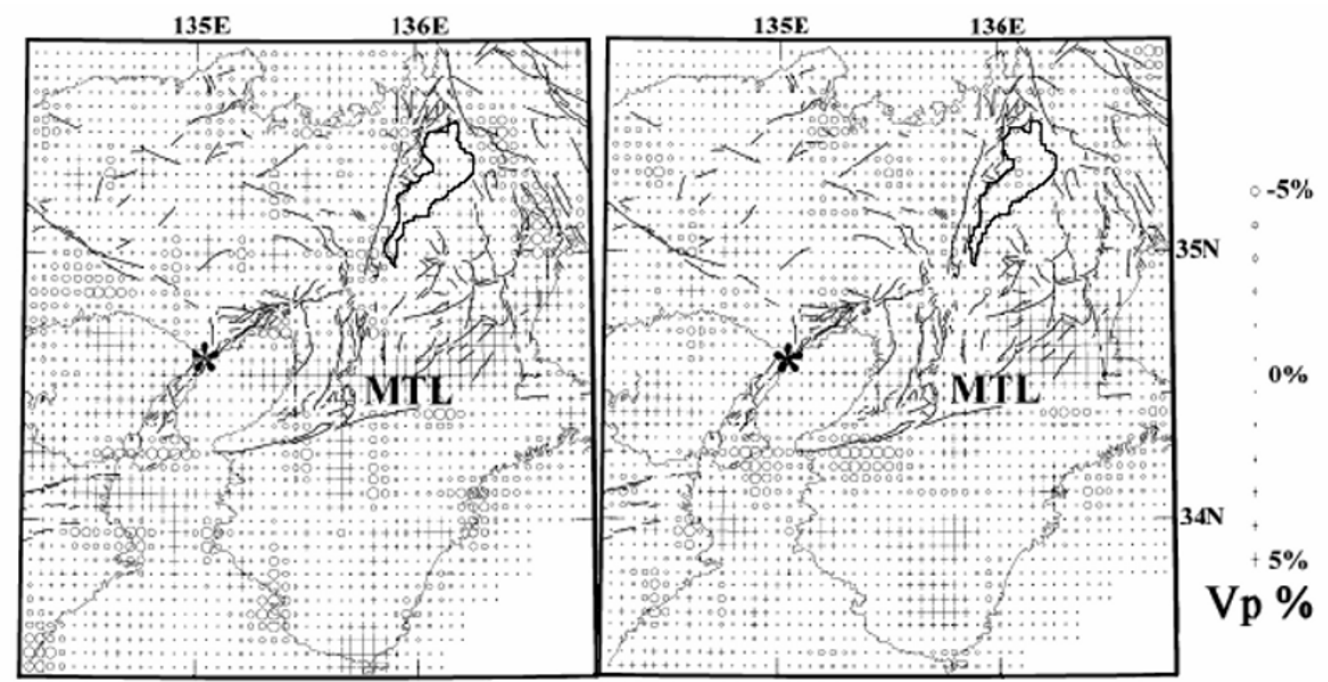

(a) Depth $=2 \mathrm{~km}$

(b) Depth $=15 \mathrm{~km}$

Fig. 20. Lateral variations of $P$-wave velocity in the study area (Salah and Zhao, 2003). Circles and crosses denote low and high velocities, respectively. Star represents the epicentre of 1995 Kobe mainshock. Thin lines show active faults. MTL is the Median Tectonic Line.

examine the sensitivity of synthetics to the source and structure parameters. These sensitivity tests show the reliability of using the cross-correlation as the evaluation tool. These tests are employed to investigate the effects of the different velocity and source parameters on synthetic seismograms for extracting fruitful information on the wave propagation.

The tests conducted for the focal mechanisms show that the waveform modelling results agree with the focal mechanism solutions estimated from the $P$-wave polarity data. It is important to note that, to estimate the focal mechanism with a single station, the hypocentral parameters and the velocity model must be known accurately (Dreger, 1993; Thio et al., 1999).

The tests performed for the velocity models show that the surface layer, Conrad depth and the upper-crust velocity have greater effects on the synthetic seismogram. It is found that the detection of a very thin surface layer is not an easy task. There can be trade-off between the layer thickness and layer velocity when using a single station. However, for relatively thick surface layer this trade-off diminishes and the estimation is feasible. The surface layer is necessary to calibrate and fit the observed arrival times. We have successfully modelled the 29 paths with suitable $1-\mathrm{D}$ velocity models. The effect of Biwa Lake is examined by studying the Biwa and non-Biwa paths. The results of the waveform modelling indicate that there are considerable lateral variations in the crustal structure beneath the study area. 


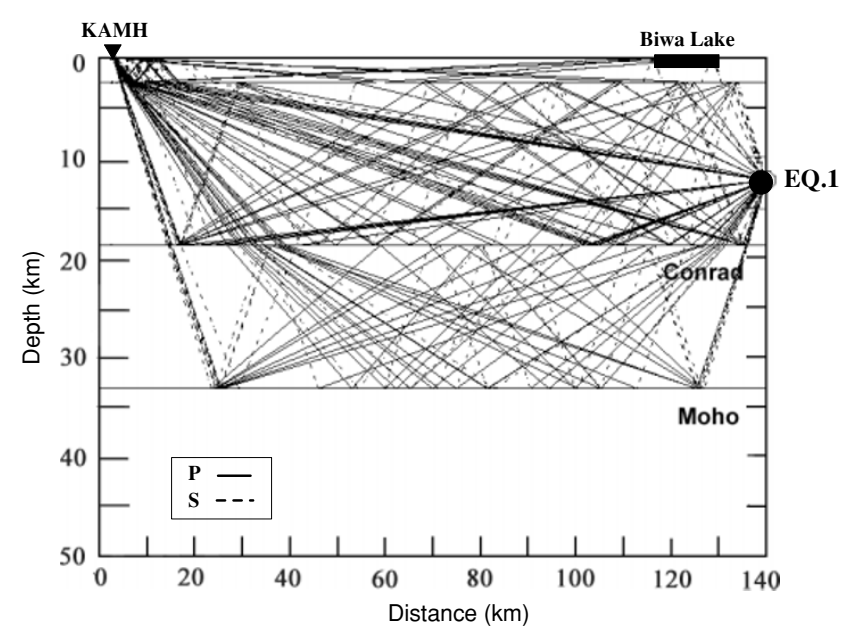

Fig. 19. The geometrical ray distribution along the path EV1-KAMH. The location of Biwa Lake, event 1 hypocenter and the KAMH station are shown.

The western area, constrained by ray paths to stations IZSH and KAMH, has large Conrad and Moho depths. The deepest Conrad and Moho discontinuities are found to be 19 and $33.0 \mathrm{~km}$, respectively. The central portion of the study area is constrained by paths to stations OBMH, OTUH and MYMH. The path EV2-OBMH gives a Moho depth of 30 $\mathrm{km}$ and a Conrad depth of $16.8 \mathrm{~km}$, while the models for paths to stations MYMH and OTUH are less reliable due to their short path lengths. The northeastern area is sampled by paths to stations EIHH, OTAH, TRGH and NEOH. The average Conrad and Moho depths beneath those stations are 16.7 and $28.4 \mathrm{~km}$, respectively.

The eastern area is influenced by Biwa Lake and is sampled by paths to stations HMAH, TAGH, HNOH and SGRH. Their average Conrad and Moho depths from the non-Biwa paths are 16.8 and $28.5 \mathrm{~km}$, respectively. From the difference between the common station non-Biwa and Biwa paths, we found that the resulted discontinuities in the Biwa models are deeper by $1-3 \mathrm{~km}$ than those of the surrounding areas.

Although the waveform modelling yields good waveform matching, the obtained velocity structure beneath Biwa Lake is still a rough 1-D approximation. The resulted models generally reflect the structure beneath the stations HMAH, TAGH, HNOH and SGRH and the velocity structure beneath the lake is not accurately estimated unless the whole path lengths lie beneath the lake. However, the Biwa Lake effects on the different paths are visible from the waveform modellings. The Biwa models show depths of 19 and $31 \mathrm{~km}$ for the Conrad and Moho, respectively, which are deeper than the corresponding non-Biwa paths by 1-3 $\mathrm{km}$.

Salah and Zhao (2004) inverted the $P m P$ - $P$ differential times and estimated the Moho depth in this area as 31$32 \mathrm{~km}$ under the land area and 29-30 km under the Japan sea coast. Zhao et al. (1992) estimated the Conrad and Moho depth distribution and found their ranges to be 1518 and 32-34 km, respectively, for SW Japan. The results of the two previous studies are generally consistent with this study, though the Moho depth by Zhao et al. (1992) is deeper by $2-3 \mathrm{~km}$. Both Zhao et al. (1992) and Salah and Zhao (2004) found no local structural variations beneath Biwa Lake perhaps due to the lower spatial resolution of their data sets. Salah and Zhao (2003) revealed lateral velocity variations of up to $5 \%$ beneath this area (Fig. 20). Yamauchi et al. (2003) and Kudo and Yamaoka (2003) found the deepening of the Conrad and Moho discontinuities beneath Biwa Lake from receiver function analyses and gravity anomaly data. For determining more detailed crustal structure under such a complex area, 2-D or 3-D waveform modellings and high-resolution seismic tomography are needed in future studies.

Acknowledgments. The authors wish to thank D. V. Helmberger for allowing us to use his GRT code and S. Ni for technical help. We also thank G. Fan for advices and fruitful discussion. We appreciate the National Research Institute for Earth Sciences and Disaster Prevention (NIED) in Japan for maintaining and supplying the high quality waveform data used in this study. Generic Mapping Tools (GMT) by Wessel and Smith and "Computer Programs in Seismology" by R. B. Herrmann are used for plotting some of the figures. E. Fukuyama and two anonymous referees critically read the manuscript and provided us with helpful comments, which improved the manuscript. This work was partially supported by grants (Kiban B-11440134 and Kiban A-17204037) to D. Zhao from Japan Society for the Promotion of Science.

\section{References}

Ali, M., H. Oda, A. Hayashida, K. Takemura, and M. Torii, Holocene paleomagnetic secular variation at Lake Biwa, central Japan, Geophys. J. Int., 136, 218-228, 1999.

Blair, D. P. and A. T. Spathis, Seismic source influence in pulse attenuation studies, J. Geophys. Res., 89, 9253-9258, 1984.

Dreger, D., Modeling earthquakes with local and regional broadband data, Ph.D. Thesis, California Institute of Technology, Pasadena, California, 1993.

Dreger, D. and D. V. Helmberger, Broad-band modeling of local earthquakes, Bull. Seism. Soc. Am., 80, 1162-1179, 1990.

Dreger, D. and D. V. Helmberger, Determination of source parameters at regional distances with three-component sparse network data, J. Geophys. Res., 98, 8107-8125, 1993.

Helmberger, D. V., Generalized ray theory for shear dislocations, Bull. Seism. Soc. Am., 64, 45-64, 1974.

Helmberger, D. V., Theory and application of synthetic seismograms in earthquakes: Observation, theory and interpretation, Proc. Int. Sch. Phys, 'Enrico Fermi' course LXXXV, edited by H. Kanamori and E. Boshi, pp. 174-221, North-Holland, Amsterdam, 1983.

Helmberger, D. V., X. J. Song, and L. Zhu, Crustal complexity from regional waveform tomography: Aftershocks of the 1992 Landers earthquake, California, J. Geophys. Res., 106, 609-620, 2001.

Jones, L. E. and D. V. Helmberger, Earthquake source parameters and fault kinematics in the eastern California shear zone, Bull. Seism. Soc. Am., 88, 1337-1352, 1998.

Kudo, T. and K. Yamaoka, Pull-down basin in the central part of Japan due to subductions-induced mantle flow, Tectonophysics, 367, 203-217, 2003.

Langston, C. A., Local earthquake wave propagation through Mississippi embayment sediments, Part I: Body-wave phases and local site responses, Bull. Seism. Soc. Am., 93, 2664-2684, 2003.

Langston, C. A. and D. V. Helmberger, A procedure for modelling shallow dislocation sources, Geophys. J. R. Astron. Soc., 42, 117-130, 1975.

Mori, J. and D. V. Helmberger, Large amplitude Moho reflections (SmS) from Landers aftershocks, southern California, Bull. Seism. Soc. Am., 86, 1845-1852, 1996.

Obara, K., Nonvolcanic deep tremor associated with subduction in southwest Japan, Science, 296, 1679-1681, 2002.

Ohtake, M., Temporal change of $Q_{p}^{-1}$ in focal area of 1984 western Nagano, Japan, earthquake as derived from pulse width analysis, J. Geophys. Res., 90, 4846-4852, 1987.

Saikia, C. K. and L. J. Burdick, Fine structure of $\mathrm{P}_{\mathrm{nl}}$ Waves from Explosions, J. Geophys. Res., 96, 14,383-14,401, 1991. 
Saikia, C. K., B. B. Woods, and H. K. Thio, Calibration of the regional crustal waveguide and the retrieval of source parameters using waveform modelling, Pure Appl. Geophys., 158, 1301-1338, 2001.

Salah, M. K. and D. Zhao, 3-D seismic structure of Kii Peninsula in southwest Japan: evidence for slab dehydration in the forearc, Tectonophysics, 364, 191-213, 2003.

Salah, M. K. and D. Zhao, Mapping the crustal thickness in southwest Japan using Moho reflected waves, Phys. Earth Planet. Int., 141, 7994, 2004.

Savage, B., C. Ji, and D. V. Helmberger, Velocity variations in the uppermost mantle beneath the southern Sierra Nevada and Walker Lane, $J$. Geophys. Res., 108(B7), 2325, doi: 10.1029/2001JB001393, 2003.

Scherbaum, F., Of Poles and Zeroes, Fundamentals of Digital Seismology, Kluwer academic publishers, 1996.

Song, X. J. and D. V. Helmberger, Pseudo green's functions and waveform tomography, Bull. Seism. Soc. Am., 88, 304-312, 1998.

Tani, H., A study on the 3-D crustal structure of southwest Japan, Thesis, Ehime Univ., 53, 2002.

Thio, H. K., X. Song, C. K. Saikia, D. V. Helmberger, and B. B. Woods, Seismic source and structure estimation in the western Mediterranean using a sparse broadband network, J. Geophys. Res., 104, 845-861, 1999.

Wallace, T. C., D. V. Helmberger, and G. R. Mellman, A technique for the inversion of regional data in source parameter studies, J. Geophys. Res., 86, 1679-1685, 1981.
Yamauchi, M., K. Hirahara, and T. Shibutani, High resolution receiver function imaging of the seismic velocity discontinuities in the crust and the uppermost mantle beneath southwest Japan, Earth Planets Space, 55, 59-64, 2003.

Zhao, L. S. and D. V. Helmberger, Source estimation from broadband regional seismograms, Bull. Seism. Soc. Am., 84, 92-104, 1994.

Zhao, D., S. Horiuchi, and A. Hasegawa, Seismic velocity structure of the crust beneath the Japan islands, Tectonophysics, 212, 289-301, 1992.

Zhao, D., A. Hasegawa, and H. Kanamori, Deep structure of Japan subduction zone as derived from local, regional and teleseismic events, $J$. Geophys. Res., 99, 22313-22329, 1994.

Zhao, D., F. Ochi, A. Hasegawa, and A. Yamamoto, Evidence for the location and cause of large crustal earthquakes in Japan, J. Geophys. Res., 105, 13579-13594, 2000.

Zhao, D., O. P. Mishra, and R. Sanda, Influence of fluids and magma on earthquakes: seismological evidence, Phys. Earth Planet. Inter., 132, 249-267, 2002.

Zhu, L. and D. V. Helmberger, Advancement in source estimation techniques using broadband regional seismograms, Bull. Seism. Soc. Am., 86, 1634-1641, 1996

M. F. Abdelwahed (e-mail: mfarouk@sci.ehime-u.ac.jp) and D. Zhao (e-mail: zhao@sci.ehime-u.ac.jp) 